\title{
"SUA VI, SUA NATURA, SUA SPONTE SACRUM". LE MARIAGE DANS LA JURISPRUDENCE DE LA ROTE ROMAINE DU CONCILE DE TRENTE A LA PREMIERE CODIFICATION CANONIQUE
}

\author{
"SUA VIA, SUA NATURA, SUA SPONTE SACRUM". \\ MARRIAGE IN THE JURISPRUDENCE OF THE ROMAN ROTA \\ FROM THE COUNCIL OF TRENTO TO THE FIRST CANONICAL \\ CODIFICATION \\ "SUA VIA, SUA NATURA, SUA SPONTE SACRUM”. EL \\ MATRIMONIO EN LA JURISPRUDENCIA DE LA ROTA \\ ROMANA DEL CONCILIO DE TRENTO A LA PRIMERA \\ CODIFICACIÓN CANÓNICA
}

Angela SANTANGELO CORDIANI ${ }^{1}$

Universidad degli Studi de Milán, Italia

Reçu: 27 Juin 2021 / Accepté: 26 Juillet 2021

\section{Résumé}

La réforme du mariage était l'une des questions les plus épineuses affrontées par le Concile de Trente. Le célèbre décret Tametsi introduisait la modification substantielle selon laquelle, pour qu'il soit valable, le consentement des futurs époux devait être accompagnée de la célébration in facie ecclesiae, en présence du proprius parochus et de deux ou trois témoins, sans imposer l'approbation paternelle. La Rote Romaine aura le rôle fondamental de garantir, pendant plus de trois siècles, l'application des canons de Trente et d'intervenir, sur le plan interprétatif, afin de définir les éléments restés ambigus ou irrésolus lors du Concile. La court suprême a ainsi gardé sa position traditionnelle de prééminence dans l'organisation judiciaire de l'Eglise, son rôle de guide et sa fonction propulsive dans l'évolution et dans l'adaptation de l'organisation juridique face aux exigences changeantes des temps et de la société.

Mots clés: Concile de Trente, Rote Romaine, Eglise catholique, Mariage, Codification canonique, Jurisprudence

\begin{abstract}
Marriage reform is one of the most complex issues dealt with by the Council of Trento. The decree Tametsi introduced the radical innovation of the celebration in facie ecclesiae in the presence of the parish priest and two or three witnesses, without imposing paternal consent. The Roman Rota had the fundamental role of guaranteeing the application of the canons of Trento for more than three centuries and of intervening in an interpretative way to define the elements that remained ambiguous or unresolved in the Council. The supreme tribunal thus maintained for centuries its
\end{abstract}


“SUA VI, SUA NATURA, SUA SPONTE SACRUM". LE MARIAGE DANS LA JURISPRUDENCE DE LA ROTE ROMAINE... Angela SANTANGELO CORDIANI

2

traditional position of pre-eminence in the judicial organization of the Church and its propulsive function in the evolution and adaptation of the juridical order in the face of the changing needs of the times and of society.

Keywords: Council of Trento, Roman Rota, Marriage, Canonical codification, Jurisprudence, Catholic Church 


\section{Resumen}

La reforma del matrimonio ha sido una de las cuestiones más espinosas a las que se ha enfrentado el Concilio de Trento. El célebre decreto Tametsi introducía una modificación sustancial, según la cual, para que el matrimonio fuera considerado válido, el consentimiento de los futuros esposos debía estar acompañado de la celebración in facie ecclesiae, en presencia del proprius parochus y de dos o tres testigos, sin necesidad de la imposición u obligación de la aprobación paterna. A la Rota Romana le corresponderá desempeñar el rol fundamental de garantizar, durante más de tres siglos, la aplicación de los cánones de Trento y por ello, intervenir, desde un punto de vista interpretativo, a fin de definir los elementos considerados ambiguos o irresolubles de los contenidos del Concilio. La Corte suprema conserva así su tradicional posición de preeminencia en la organización judicial de la Iglesia, así como su papel de guía y su función propulsiva en la evolución y adaptación de la organización jurídica de cara a las exigencias cambiantes de la sociedad que se adapta a los nuevos tiempos.

Palabras clave: Concilio de Trento, Rota Romana, Iglesia católica, Matrimonio, Codificación canónica, Jurisprudencia 
Il est notoire que la réforme du mariage était l'une des questions les plus épineuses affrontées par le Concile de Trente. ${ }^{2}$ La Rote Romaine, suprême organe judiciaire de l'Eglise catholique et tribunal civil de dernière instance au sein des Etats pontificaux, ${ }^{3}$ aura le rôle fondamental -à côté de la Congrégation du Concile- de garantir, pendant plus de trois siècles, l'application des canons de Trente et d'intervenir, sur le plan interprétatif, afin de définir les éléments restés ambigus ou irrésolus lors du Concile.

Dès les premières sessions bolonaises du Concile, au cours des années 1545-48, dédiées plus particulièrement aux questions dogmatiques, le caractère sacramental du lien, contesté et rejeté par la doctrine protestante, avait été réitéré dans le décret De sacramentis du 3 mars $1547 .^{4}$

Cependant, ce n'est que vers la fin de 1563 que le très célèbre et controversé décret Tametsi, qui introduisait des modifications substantielles en matière de mariage, fut approuvé à une large majorité. ${ }^{5}$ Cette décision fut adoptée après une longue interruption des travaux (due à l'opposition des protestants et, surtout, à la reprise des conflits contre Charles V) et suite à un débat brûlant qui se poursuivit pendant plusieurs mois, au cours de la célèbre vingt-quatrième session, qui avait abouti à plusieurs reprises à un échec, vue l'impossibilité de parvenir à un accord entre deux orientations opposées: les partisans de la conception traditionnelle du mariage, se basant typiquement sur le consentement, et ceux qui exigeaient des formes rigoureuses de publicité et de transcription, au nom de l'exigence de certitude. ${ }^{6}$

Trois questions étaient affrontées dans le décret: le consentement des parents des futurs époux, la nécessité des publications et la forme de célébration des noces: trois aspects étroitement liés au problème des mariages clandestins, considérés comme le défaut principal du droit matrimonial classique, longuement dénoncé à plusieurs reprises et devenu d'autant plus grave face aux critiques soulevées par la Réforme protestante. ${ }^{7}$

Selon la doctrine canonique classique, élaborée à partir du XII. siècle, il n'existait aucune forme spécifique de célébration du mariage car, pour la validité de l'union, l'Eglise considérait qu'il suffisait que le consentement mutuel entre les futurs époux soit exprimé par verba de praesenti, ce qui indiquait le temps présent de l'action mise en œuvre ("je te prends comme mon épouse, mon époux"). Les mêmes mots prononcés de futuro équivalaient, par contre, à une promesse de mariage. ${ }^{8}$

Le décret Tametsi introduisait l'innovation radicale selon laquelle, pour qu'il soit valable, le consentement des futurs époux devait être accompagnée 
de la célébration in facie ecclesiae, en présence du proprius parochus et de deux ou trois témoins, et précédé par la publication des bans dans la même église, pendant trois dimanches consécutifs avant la cérémonie, durant la messe: le but était de solliciter les oppositions éventuelles au projet de mariage, en consentant aux fidèles d'informer le curé de l'existence d'empêchements, comme le lien de parenté jusqu'au quatrième degré, un cas d'espèce très récurrent dans les recueils des décisions de la Rote. ${ }^{9}$ Les trois publications pouvaient, toutefois, être réduites à une seule, voire même être dispensées, s'il y avait la crainte que des empêchements faux ou spécieux risquaient d'être apportés pour entraver les noces de manière frauduleuse. Dans les autres cas, leur absence n'entraînait pas la nullité du mariage, mais seulement son illégitimité.

Comme cela ressort également de la jurisprudence rotale, l'évêque possédait un pouvoir discrétionnaire plutôt important au niveau de la dispense des publications: de cette manière, était réalisé un mariage secret, mais pas clandestin, une nouvelle institution créée, en quelque sorte, indirectement par le décret Tametsi, lorsque les époux exprimaient la volonté d'éviter que la célébration du mariage soit soumise à toute forme de publicité. D'après les recueils des décisions, il ressort que la plupart du temps il y avait, à la base, la volonté de transformer une relation de concubinage en mariage: les noces étaient inscrites dans un registre spécial conservé auprès de la chancellerie épiscopale, accessible uniquement aux autorités ecclésiastiques, en régularisant ainsi, vis-à-vis de sa propre conscience, une union considérée coupable et socialement inconvenante..$^{10}$

Des formes de publicités avaient, par ailleurs, été encouragées par l'Eglise, même au cours de la période précédant le Concile, sans toutefois que les noces célébrées en leur absence n'aient été considérées comme nulles: dans la pratique, les personnes qui se mariaient clandestinement commettaient un péché, mais, si le mariage était fondé sur le libre consentement, il était valable à tous les effets et assurait la légitimité des enfants et la transmission héréditaire des biens. ${ }^{11}$

L'accent mis par l'Eglise médiévale sur le libre consentement des futurs époux contrastait cependant avec la conception séculaire du mariage, dominant dans tous les milieux sociaux, qui l'insérait dans un contexte plus large de stratégies et d'accords entre les familles: qu'il s'agisse de familles princières ou plus modestes et même dans le milieu rural et paysan, il était rare que les parents ne soient pas impliqués dans l'accord de mariage, dans le but de créer de nouvelles alliances ou de consolider celles déjà existantes. Une intervention qui se limitait parfois à un conseil prudent, mais qui consistait souvent en une 
imposition autoritaire, indépendamment de l'âge des enfants, vu le caractère viager de la puissance paternelle romaine: une interférence qui était encore plus encombrante et intransigeante à l'égard des filles, soumises à une discipline paternelle encore plus rigide, pour éviter que les dots concédées à l'occasion des noces ne se dispersent dans les couches les plus basses de la hiérarchie sociale. $^{12}$

En définitive, le père -ou, en son absence, un autre homme membre de la famille- dirigeait le choix des futurs époux, en fonction d'exigences de défense et de renforcement des patrimoines, sur lesquels il était nécessaire que les pères exercent un contrôle prépondérant, spécialement au sein de l'aristocratie et de la bourgeoisie. D'où le comportement assez hostile à l'encontre des mariages clandestins, conclus sans l'approbation paternelle et en l'absence de publicité, qui s'était traduite en prévisions statutaires de sanctions rigoureuses, principalement pécuniaires, comme le déshéritement et la perte de la dot.

D'autre part, l'Eglise aussi était consciente des dangers liés à l'approche purement consensuelle du mariage, à cause de la difficulté de fournir des preuves irréfutables de l'échange des consentements de praesenti.

En marge des risques plus graves représentés par les cas de bigamie, ${ }^{13}$ l'Eglise ne pouvait plus tolérer le désordre provoqué par un acte se fondant exclusivement sur la liberté de conscience des époux. La tâche difficile des tribunaux ecclésiastiques qui, au moins depuis le XII. siècle, avaient revendiqué la juridiction exclusive sur le mariage en tant que matière sacramentelle, avait été jusqu'à ce moment-là, la vérification de la validité d'un engagement contracté en dehors de toute forme et solennité, fuyant à tout contrôle et dépourvu d'éléments de preuve. Ensuite, l'autre difficulté était de distinguer le mariage, dans le sens strict du terme, par rapport à une simple promesse, car la différence entre les deux engagements, dont les essences respectives sont bien distinctes, était représentée exclusivement par le temps utilisé pour la conjugaison des verbes, à savoir le présent ou le futur.

De plus, dans les spéculations de la science canonique, la différence entre la promesse et le mariage était d'autant plus abstraite et insaisissable lorsque la promesse était suivie par le rapport charnel, qui engendrait un mariage présumé, puisque l'acte physique impliquait naturellement un consentement concomitant. $^{14}$

La tâche du Concile fut donc d'affronter la question des mariages clandestins qui souciait également les sommets du pouvoir séculier, tout en prenant ses distances par rapport aux positions exprimées par les réformateurs: ceux-ci, même s'il existait des différences manifestes entre les diverses 
communautés, étaient tous d'accords pour rejeter la conception sacramentelle du lien, en attribuant la compétence juridictionnelle aux tribunaux séculiers, et introduisaient l'obligation du consentement paternel pour les enfants mineurs, ainsi que la célébration solennelle en présence du pasteur et des témoins, afin de contraster la clandestinité. ${ }^{15}$

L’idée qui prévalut au cours du Concile fut celle plus encline à valoriser la tradition de l'Eglise, vieille de plusieurs siècles, qui fondait le mariage sur le libre consentement, en dépit des instances, pourtant bien représentées, spécialement par les prélats français et espagnols, qui considéraient le consentement paternel comme une condition essentielle sur base du quatrième commandement du décalogue "Honore ton père".

Malgré cela, le compromis adopté innova profondément la doctrine originaire se basant sur le consentement et interrompit une tradition plus que millénaire: exiger la célébration publique et solennelle du mariage comme conditio sine qua non de sa validité, en sanctionnant son inobservance par la nullité du lien, était le moyen le plus efficace pour éviter les mariages clandestins, souvent suivi par des deuxièmes noces ou des abandons. D'autre part, était mis fin aux contentieux fréquents qui débouchaient sur des procès concernant la signification de praesenti ou de futuro des paroles prononcées par les époux.

Par contre l'approbation paternelle ne fut pas imposée, plutôt, sous menace d'anathème, il était interdit à ceux qui exerçaient une autorité sur un homme ou sur une femme de forcer leur volonté en violation du principe fondamental de la liberté du mariage. Ceci dit, le décret, fruit de la conciliation délicate entre des positions vivement opposées, précisait que 1'Eglise détestait les mariages contractés sans le consentement des parents, et cette réprobation permettait de satisfaire partiellement les évêques transalpins. ${ }^{16}$

Cependant, en dépit de la prohibition de Trente, la clandestinité ne disparut pas, comme l'atteste la jurisprudence rotale, sous la forme, encore en plein dixseptième siècle, d'unions conclues sans formes extérieures, à travers le simple échange des consentements pour éluder la désapprobation paternelle. ${ }^{17}$

D’après ce qui ressort des contentieux, le parcours vers le mariage légitime pouvait être bloqué pour les motifs les plus variés: opposition des familles, changement d'avis de l'un des deux fiancés, interventions d'autrui qui revendiquait une priorité sur base d'un engagement pris auparavant avec l'un des futurs époux, mais surtout lorsque l'échange des promesses avait été imposé par la famille: dans ce cas, les décisions de la Rote allaient toujours 
dans le sens des parties requérantes, au détriment de la volonté paternelle, au nom du libre choix. ${ }^{18}$

Ceci dit, il y a toutefois lieu de souligner que dans les décisions rotales il y avait plusieurs manifestations de préférence explicite pour les mariages "inter pares", aussi bien du point de vue de l'âge que de celui de la couche sociale et des possibilités économiques familiales, pour éviter "pericula et dissidia", ${ }^{19}$ bien que leur complète validité était toutefois confirmée. ${ }^{20}$ Par exemple, l'auditeur de la Rote Paolo Rubeo, dans une annotation relative à une décision des années vingt du dix-septième siècle, n'hésita pas à préconiser "infaustos exitus" pour les "matrimonia inita inter amore excaecatos", c'està-dire ceux qui étaient généralement célébrés en secret et en l'absence du consentement des parents. ${ }^{21}$

D'après les recueils de jurisprudence, bien souvent au cours des décennies qui suivirent immédiatement l'entrée en vigueur du décret, il ressort nettement la figure du célébrant en la personne du curé de la paroisse. Le motif de ce choix résidait dans le fait que le célébrant devait connaître les futurs époux ou, au moins, être en condition d'acquérir facilement des informations sur leur compte.

Le curé de la paroisse était donc celui du domicile des futurs époux ou d'un des deux, comme cela a notamment été clarifié à plusieurs reprises par la Rote. ${ }^{22}$ Cependant, le concept de domicile, pendant toute l'époque du droit savant, était entendu dans une acception très large, comprenant aussi une résidence temporaire ou un quasi-domicile, ce qui ne simplifiait pas toujours l'identification du domicile parmi une pluralité de demeures fréquentées de la même manière par les futurs époux.

Dans ces cas, devenait décisif l'animus, à savoir l'intention d'élire domicile dans une localité précise plutôt que dans une autre, selon une interprétation fournie au cours du dix-septième siècle par le grand juriste et juge de la Rote Romaine Giovanni Battista De Luca, destinée à faire école jusqu'au début du vingtième siècle. ${ }^{23}$

Dans tous les cas, l'évêque, ou directement le curé, avait toujours la possibilité d'autoriser un autre prêtre, un cas assez courant dans la pratique: tout autre prêtre qui avait osé unir en mariage ou bénir les noces était de iure suspendu a divinis. Jusqu'à la fin du dix-septième siècle, de nombreuses décisions se penchèrent sur les conditions requises pour la validité de la délégation, en faisant prévaloir une interprétation assez large et souple, 
qui admettait également une délégation non spécifique, mais générale "ad exercenda iura parochialia". ${ }^{24}$

Le célébrant avait le devoir de vérifier la liberté de choix des futurs époux, l'absence de contraintes extérieures et d'empêchements à travers les publications pendant trois dimanches consécutifs; il devait présider la cérémonie, bénir les époux et transcrire le mariage dans les registres paroissiaux, en indiquant le nom des époux et celui des témoins. Bien évidemment, comme le précisait les juges, les futurs époux, mais aussi les témoins, devaient être en pleine possession de leurs facultés mentales, avec exclusion des personnes en état d'ébriété, des endormis et des enfants. Par contre, les consanguins étaient admis, en dérogation aux règles communes en matière de preuve par témoins et en syntonie avec la nature spécifique et l'essence du rite nuptial. ${ }^{25}$

Dans le cadre des litiges matrimoniaux, aussi bien le registre paroissial que les témoins représentaient une preuve parfaite de la célébration effective des noces. La preuve par témoins était admise en cas d'omission de l'inscription ou de perte du registre, même si cette perte n'était pas entièrement prouvée: à ce propos la Rote était indiscutablement très souple au nom du favor matrimonii. ${ }^{26}$

C'est ainsi que par analogie, le tribunal suprême n'admettait pas la preuve par témoins contre le registre paroissial. Parallèlement, une ample casuistique attestait que, dans les causes de succession ou de légitimation des enfants, dans lesquels la question du mariage était abordée uniquement d'une manière incidente, il était suffisant d'apporter une simple preuve semi-pleine du mariage, fournie par des présomptions comme la réputation ou la longue cohabitation more uxorio ou d'autres indices similaires. ${ }^{27}$

Le Concile n'avait absolument pas clarifié le rôle du prêtre et ceci permettait à chaque diocèse d'organiser librement leur rituel. Le décret Tametsi avait proposé, sans l'imposer, la formule "Ego vos in matrimonium coniungo", qui semblait attribuer au célébrant le rôle actif de ministre du sacrement. Malgré cela, les rituels locaux avaient la liberté de s'écarter de cette expression et de recourir à des formules différentes: dans beaucoup de diocèse, parmi lesquels Milan et Rome, avait été adoptée la formule "Que l'homme ne sépare pas ce que Dieu a uni", qui amoindrissait davantage le rôle du curé. ${ }^{28}$ La Rote préférait ce deuxième courant de pensée et estimait suffisantes "quaelibet verba apta ad significandum mutuum consensum". ${ }^{29}$ Du reste, la cour suprême reconnaissait la validité des mariages contractés en présence d'un prêtre contraint à assister au mariage malgré lui, au moyen de la tromperie, voire même de la force, pour autant qu'il soit en mesure d'entendre les paroles d'engagement de praesenti, 
comme c'est arrivé dans le fameux mariageà surprise décrit dans le premier et plus renommé roman historique italien, "I promessi sposi" de Alessandro Manzoni du $1840 .^{30}$

Le débat était donc destiné à rester ouvert en doctrine, en oscillant entre ceux qui, à l'instar de Melchiorre Cano, dans ses Lieux théologiques, rejetaient la thèse des futurs époux comme ministres du sacrement l'un vis-à-vis de l'autre, et autres influents théologiens, comme Soto et Bellarmino, fervents défenseurs de l'opinion contraire. Un débat destiné à ne recevoir aucune réponse, même pas de la part des hautes sphères de l'Eglise: si Benoît XIV, dans son De synodo diocesana, à la moitié du dix-huitième siècle, étayait la doctrine selon laquelle le prêtre devait être considéré comme ministre du sacrement, au cours de la même période, la Congrégation du Concile estimait que l'interprétation opposée était "plus véritable et plus acceptée".

Au cours du dix-septième siècle les solennités introduites par le Concile de Trente étaient désormais bien ancrées dans la conscience sociale et la partie la plus importante des litiges présentés devant le tribunal suprême avait pour objet l'inaccomplissement de la promesse de mariage exprimée dans les sponsalia, institution laissée inchangée par le Concile, qui se soustrayait facilement à toute forme de contrôles extérieurs. ${ }^{32}$

C'est donc principalement en matière de fiançailles que la Rote joua un rôle décisif, suite au silence du Concile à ce propos, à l'exception de la prévision de l'empêchement d'honnêteté publique, par le biais duquel on interdisait le mariage, après la rupture des fiançailles, entre l'un des ex-fiancés et un parent de l'autre. ${ }^{33}$

En s'inspirant d'une idée extraite des Saintes Ecritures, le droit canonique classique avait prévu l'obligation de maintenir la promesse de mariage échangée avec le libre consentement et à un âge non inférieur à sept ans qui pouvait être abandonnée uniquement moyennant le consentement des deux fiancés ou dans des cas exceptionnels: la rupture injustifiée du lien créait non seulement de la haine et de l'animosité entre les deux familles, dont les racines plongeaient évidemment dans le droit germanique, mais légitimait aussi le recours au tribunal ecclésiastique en vue d'obtenir l'accomplissement de la promesse. $^{34}$ Dans ce cas aussi, comme dans le cas des noces, il n'était facile de prouver le consentement mutuel exprimé avec les mots de futuro, s'il était advenu en l'absence de témoins.

Pour compliquer ce tableau, une autre circonstance venait s'ajouter : en effet, comme on a vu, selon le droit canonique classique et les pratiques sociales enracinées, vu l'engagement important qu'ils comportaient, les mots 
de futuro légitimaient le rapport sexuel, ce qui donnait naissance au mariage présumé.

La jurisprudence rotale post-Concile de Trente conservait encore quelques traces de cette institution, surtout au niveau de litiges entamés en première instance à l'époque préconciliaire, mais aussi en partie pour des litiges survenus par la suite. Tout cela parce que la volonté du Concile de détourner l'attention sur le moment solennel de la célébration des noces comme acte fondant le lien de couple ne fut pas immédiatement compris et appliqué dans toutes les couches sociales, surtout dans les cas où les fiançailles étaient formalisées en présence du curé et de deux témoins, dans un contexte externe tout à fait analogue à celui prévu par le Concile pour les véritables noces. ${ }^{35}$

Il existait aussi des cas où les avocats des parties faisaient revivre l'ancienne institution du mariage présumé dans leurs stratégies de défense, en vue d'obtenir la reconnaissance d'un lien conjugal lorsque l'échange des mots d'engagement pour le futur était suivi par un rapport charnel: autant dire que, dans l'intérêt évident d'une des parties, la morale devait supplanter le droit, même devant la justice... ${ }^{36}$

La plupart des demandes qui visaient l'accomplissement de la promesse de mariage provenaient de femmes jeunes ou de veuves enceintes, abandonnées par le séducteur, ce qui attestait, entre autre, la fréquence élevée des rapports avant le mariage. La promesse de l'homme légitimait la disponibilité de la femme, qui cédait seulement après une promesse de mariage claire et explicite: il s'agit-là de la trame récurrente dans les procédures intentées pour obtenir l'accomplissement de la promesse ou, du moins, un dédommagement adéquat.

Dans les décisions de la Rote, ce thème des promesses de mariage non maintenues se croisait souvent avec celui du viol pur et simple, perpétré contre la volonté de femmes vierges, en usant la flatterie et la séduction: un délit relevant de la compétence des juges séculiers, punissable avec la peine de mort, aussi bien par le droit romain que par la réglementation statutaire. ${ }^{37}$

Ça va sans dire que l'arme de séduction masculine la plus efficace visant à favoriser la complaisance féminine était justement la promesse de mariage. Cependant, la soi-disant promesse de mariage, du reste totalement à démontrer, surtout si elle avait été sciemment prononcée en l'absence de témoins, comme cela advenait généralement dans ces cas, avait la force de déplacer le for compétent du tribunal laïque à celui ecclésiastique, tout à l'avantage du présumé violeur, qui avait ainsi la possibilité de se soustraire aux sanctions les plus graves prévues par le droit pénal séculier. 
Les procès tournaient généralement autour d'affaires de femmes déflorées, dont la condition oscillait, selon les points de vue, entre celle de victimes nécessitantes d'une protection de la part des institutions judiciaires, à celles d'habiles séductrices en mesure de piéger des jeunes hommes de bonne famille ingénus et inexperts. Toutefois, c'est surtout le binôme noble/séducteur pauvre/séduite qui représentait un cliché dans la casuistique judiciaire de l'ancien régime, dans la tendance consolidée de l'époque qui considérait seulement l'homme comme partie prenante dans les dynamiques de séduction, malgré que l'expérience avait démontré le remarquable éclectisme féminin dans ce contexte des relations humaines. ${ }^{38}$

Selon l'orientation constamment défendue par la Rote, le juge ecclésiastique ne pouvait pas contraindre l'auteur de la séduction à tenir sa promesse de mariage, au nom de la pleine liberté du consentement, ce qui permettait d'épargner aux familles nobles et riches l'affront de noces réparatrices avec des séduites d'un rang social plus bas. ${ }^{39}$

Cette pratique judiciaire, largement répandue à l'époque moderne et partagée par les autres tribunaux suprêmes et même par le Sénat de Milan, ${ }^{40}$ allait à contre-courant de la doctrine canonique de la période classique, élaborée sur base d'un passage de l'Exode qui a été repris au début du treizième siècle parmi les recueils des décrétales, qui prévoyait l'obligation pour le séducteur de contracter mariage. ${ }^{41}$ La possibilité de choix alternatif entre les noces et les dots de dédommagement devint, par contre, un point fondamental de la jurisprudence rotale, à travers la coordination de l'ancienne norme des Saintes Ecritures avec d'autres chapitres des recueils des décrétales qui prévoyaient la possibilité de refuser les noces.

Le séducteur était obligé de doter la femme et cette dot donnée en guise de dédommagement, instrument de compensation de la virginité violée, devait être plus riche que celle que la femme aurait pu prétendre de son père à l'occasion de ses noces, car la séduite et déflorée aurait dû bien évidemment affronter de plus grandes difficultés de réinsertion sur le 'marché matrimonial'.

Parallèlement se posait aux juges de la Rote la question encore plus délicate et très récurrente dans la pratique du mariage entre le ravisseur et l'enlevée. ${ }^{42}$

Le droit romain déclarait pas valable le mariage contracté suite au rapt perpétré causa libinis, qui donc constituait un empêchement dirimant. ${ }^{43}$

Dès le début le droit canonique aussi interdisait le mariage du ravisseur avec l'enlevée, mais le considérait valable si arrivait, même par la suite, le consentement de la victime. ${ }^{44}$ Le doute des juristes, à ce point là, était si 
suffisait un consentement formulé d'une façon quelconque, ou bien s'il fallait un consentement manifesté par la fille dans la maison du père, loin de son ravisseur. Déjà à partir du quinzième siècle, la doctrine juridique majoritaire, la communis opinio, avait adhéré à cette deuxième solution, vu l'impossibilité de certifier le libre consentement de la femme, si celle-ci se trouvait encore sous l'autorité de son ravisseur. ${ }^{45}$ Cette orientation sera également approuvée par le Concile de Trente ${ }^{46}$ et défendue fermement dans les nombreuses décisions de la Rote qui dut se prononcer à ce propos. ${ }^{47}$

Une question débattue à la Rote était aussi celle des mariages mixtes, car l'empêchement à cause de la différence de religion, motif de nullité du lien, concernait uniquement les unions avec les infidèles et les non-chrétiens. ${ }^{48}$

Le mariage des catholiques avec des protestants, vu qu'ils étaient baptisés, bien qu'il soit illicite, restait valable, comme cela fut confirmé par la Rote. Cependant, l'illégalité comportait la nécessité d'une dispense papale, subordonnée à la promesse d'abjuration de l'hérétique, sous peine d'excommunication du célébrant à cause de sa transgression. ${ }^{49}$

Il n'était pas si rare que arrivaient devant les auditeurs de la Rote les mariages des ambulants, un cas prévu par le décret Tametsi, en pensant aux marchands, aux soldats, aux étrangers ou aux artisans forains, pour lesquels le prêtre était tenu de mener une enquête plus approfondie sur l'éventuelle présence d'empêchements à soumettre à l'évêque, afin de recevoir l'autorisation pour la célébration. ${ }^{50}$

Et on arrive enfin au fondement de l'indissolubilité du lien, affirmée avec décision par le droit canonique classique à partir des décrétales d'Alexandre III, retenu de droit divin pour sa corrélation avec le deuxième chapitre de la Genèse et confirmé par le Concile de Trente. ${ }^{51}$

La doctrine traditionnelle, au nom du privilège paulin, admettait la dissolution uniquement au sein d'un couple de non-croyants, lorsque l'un des deux se convertissait, en rendant la vie en commun impossible: de cette manière, le converti pouvait contracter un nouveau mariage, avec la dissolution de la première union. ${ }^{52}$

La dissolution du mariage conclu et non consommé était également admis, par le biais d'une dispense papale, dans l'hypothèse - rappelée aussi par la Rote - d'une prise des ordres de la part de l'un des deux conjoints. ${ }^{53}$

En dehors de ces deux cas, ${ }^{54}$ seule la séparation des corps était admissible, le divortio quoad thorum, qui maintenait fermement le lien pendant toute la 
vie. La séparation était prononcée par la juridiction ecclésiastique en présence d'un grave motif que le Concile avait soumis au pouvoir discrétionnaire du juge, sans énoncer des hypothèses formelles rigides. ${ }^{55}$

L'opinion publique n'était pas toujours consciente de la distinction subtile entre la séparation et la déclaration de nullité, due à un manque ou à un vice grave du consentement, à la présence d'un empêchement dirimant non dispensé et, troisième hypothèse introduite par le Concile, l'inobservance des formes requises pour la célébration des noces. En effet, la clandestinité, le vice de la célébration, l'absence de consentement des parents, la consanguinité ou l'impuissance étaient fréquemment invoqués indistinctement devant les juges de la Rote, afin d'obtenir, d'une manière ou d'une autre, la dissolution du lien. ${ }^{56}$

La Rote jouait donc un rôle fondamental pour clarifier et délimiter les domaines d'application des deux instituts distincts, en précisant qu'il y avait quatre motifs de séparation retenus dignes d'admission: l'adultère, les sévices (qui étaient les deux cas d'espèce les plus récurrents, invoqués presque toujours par les épouses), la haine mortelle et la maladie contagieuse certifiée par le biais d'une expertise médicale. ${ }^{57}$

Quant à l'adultère, cas d'espèce de par sa nature difficile à certifier, la Rote, alignée avec la doctrine prédominante, consolidée dans une décrétale de Célestin III, ${ }^{58}$ admettait sa preuve même au moyen d'indices et de présomptions, y compris la renommée et la notoriété, preuves généralement semi-pleines, certainement pas en mesure de fonder une sentence, mais bien de créer un cadre probatoire d'un certain poids si elles étaient additionnées entre elles: tout ceci s'alignait sur le principe qui régissait la matière des preuves légales, et réitéré par la Rote jusqu'à la fin du XIX ${ }^{\mathrm{e}}$ siècle, selon lequel "quae singula non prosunt, collecta iuvant". ${ }^{59}$ Ces éléments étaient soumis à l'appréciation prudente du juge, qui devait acquérir une certitude morale à travers une série de comparaisons de preuves revêtant un impact et une valeur différents.

Le pardon et la réconciliation excluaient et annulaient la demande de séparation, mais sur ce point les juges de la Rote se montraient rigoureux, en exigeant des preuves certaines qui allaient au-delà de la simple continuation de la cohabitation après l'adultère, certaines fois fruit d'un choix ou d'une nécessité dictée par de simples exigences pratiques. ${ }^{60}$

Les sévices étaient fréquemment à la base des demandes de séparation, spécialement de la part des épouses. Cependant, pour justifier une rupture du lien, selon l'orientation sur ce point extrêmement rigoureuse soutenue par 
la Rote, il était indispensable que la maltraitance soit grave ou au point de déterminer un danger de mort.

Ceci parce que, vis-à-vis de l'épouse, le mari était titulaire d'un droit-devoir de moderata castigatio ou moderata correctio, qui l'autorisait à avoir recours au fouet, en plus des mains, dans l'exercice légitime d'un pouvoir éducatif analogue à la patria potestas exercée sur les enfants. ${ }^{61}$ Les coups de poing, les gifles et même les coups de fouet ne suffisaient donc pas à intégrer la magna sevitia, mais était requise l'utilisation du bâton ou d'un autre instrument approprié pour offenser de manière significative. ${ }^{62}$

De plus, était exigée la réitération et, donc, une habitude consolidée dans le rapport de couple, au point de justifier une crainte fondée de répétition des graves maltraitances dans le futur: cet aspect requérait aussi de la part du juge un examen du profil psychologique du coupable, à mener sur base d'un large éventail de constatations de différente nature. En-dessous de ce seuil, le magistrat pouvait, au maximum, imposer au mari une cautio de non offendendo. ${ }^{63}$

Dans la réalité des faits, qui étaient reflétées fidèlement par les décisions de la Rote, la haine mortelle se confondait souvent et était associée aux sévices, car les deux conduites visaient à provoquer des dommages d'une gravité extrême chez la victime; toutefois, elle se référait à des comportements différents, qui se concrétisaient dans des menaces de mort, un attentat à la vie, surtout par empoisonnement, ${ }^{64}$ ou dans des dénonciations spécieux pour des délits punis avec la peine capitale. Ici aussi, le comportement de fond qui guidait le travail des juges de la Rote était empreint d'une extrême prudence dans la vérification de tous les aspects des affaires humaines et dans l'admission des prétentions des parties requérantes, alignées sur une orientation tendanciellement restrictive. ${ }^{65}$

Dans ces cas, le premier acte mis à exécution par le juge ecclésiastique, même de dernière instance, était une tentative de solution de la crise. Lorsque la séparation était accordée, un délai de quelques années, trois, six ou dix, était souvent fixé pour faire décanter la crise et résoudre les motifs du conflit simplement avec le temps qui passe, avec l'âge des époux qui avance et la dissipation du caractère litigieux, souvent fruit du jeune âge des parties impliquées. Alternativement le délai de la période de séparation était indéterminé et remis à la bonne volonté des parties, afin qu'elles trouvent ellesmêmes les motifs d'une réconciliation et d'une nouvelle réunion.

Par contre, légitimait une séparation immédiate et définitive la vie luxurieuse de l'un des époux, en général le mari, ou l'adultère de l'épouse avec 
un refus de pardon de la part de l'époux, après une période de réclusion de l'adultère dans un monastère, en général pendant quelques années.

Était aussi fréquemment présentée aux juges de la Rote la demande de déclaration de nullité du mariage pour impotentia coeundi, le plus souvent de la part du mari ${ }^{66}$ : celle-ci devait être assermentée non seulement par les deux époux, mais aussi par leurs parents et les personnes proches des parties (de manière générale on parle de "eorum propinqui"), retenus évidemment bien informées des dynamiques du couple au sein du cercle de la famille ou des amitiés étroites. De toute manière, des tentatives de soins médicaux devaient être mis en œuvre, mais sans mettre en danger la vie du patient et, de toute façon, au moins trois ans devaient s'écouler à partir de la célébration du mariage. ${ }^{67}$

Curieusement, il n'y a aucune référence dans les décisions rotales au sort des enfants, victimes authentiques de ces séparations, qui prouve le peu de poids que la mentalité de l'époque diffuse et acceptée également dans les milieux ecclésiastiques réservait à la progéniture, qui était cependant indiquée comme la fin principale et ultime des mariages chrétiens, même par les juges de la Rote. Leur entretien et leur éducation étaient, en général, régis par des conventions privées ou, dans le meilleur des cas, par le caractère officiel des actes notariés.

A partir du dix-huitième siècle, le développement graduel des doctrines juridictionnelles et la destitution progressive des compétences de l'Eglise aboutiront à la distinction entre le sacrement et le contrat, et reconnaitront aux autorités civiles le droit de réglementer et de juger le contrat de mariage. Tout ceci ne se réalisa pas sans de fortes oppositions de la part de l'Eglise, qui réitérait de manière insistante sa compétence exclusive pour l'absolue indivisibilité du sacrement et du contrat: le sacrement n'est pas un accessoire du contrat, comme le soutenait la doctrine de droit civil, elle n'est pas dans la bénédiction nuptiale, mais appartient à l'essence même du mariage, "sua vi, sua natura, sua sponte sacrum". Il s'agit d'affirmations qui reviennent constamment dans tous les documents pontificaux (Pie VI, Pie VII, Léon XII, Pie VIII, Grégoire XVI, Léon XIII, Pie X et Pie XI) ${ }^{68}$ et qui sont défendus par la Rote jusqu'à son déclin: en dehors du décret Tametsi il n'y avait que le concubinage, qui exposait aux peines prévues par les canons de Trente. ${ }^{69}$

Cela étant, l'intransigeante politique juridictionnelle aboutira à la destitution de la compétence du tribunal ecclésiastique, comme le démontre la diminution drastique des décisions de la Rote en matière de mariage au cours du dix- 
huitième siècle, spécialement dans la deuxième moitié, jusqu'à leur disparition totale au dix-neuvième siècle. ${ }^{70}$

Tout ceci même à cause de l'importance croissante prise au niveau juridictionnel par les Congrégations romaines et, spécialement, par la Congrégation du Concile, instituée par le pape Pie IV le lendemain du Concile (1564), avec le devoir d'interpréter les décrets de Trente, de garantir leur application et de fixer les règles de leur mise en œuvre concrète, même, cela va de soi, en matière de mariage: un organe de direction des évêques pour résoudre les doutes et les incertitudes, titulaire d'un vaste pouvoir législatif et juridictionnel pour chaque question de discipline; une institution qui, au niveau d'importance, suivait seulement la Congrégation du Saint-Office instituée vingt ans auparavant. ${ }^{71}$

En effet, au dix-neuvième siècle, la Rote fonctionna presqu'exclusivement en tant que tribunal d'appel pour les causes séculières des Etats pontificaux, jusqu'à la prise fatidique de Rome, le 20 septembre 1870, qui déterminera la fin des Etats pontificaux.

La constitution Sapienti Consilio de pape Pie X du 29 juin $1908^{72}$ fera renaître le tribunal suprême de ses cendres et dont les fonctions seront réorganisées et rétablies sous la direction de l'un des plus grands canonistes de l'époque, le cardinal Michele Lega, son premier doyen. ${ }^{73}$ La Rote recouvrait ainsi sa position traditionnelle de prééminence dans l'organisation judiciaire de l'Eglise, son rôle de guide et sa fonction propulsive dans l'évolution et dans l'adaptation de l'organisation juridique face aux exigences changeantes des temps et de la société, tout en réduisant progressivement son activité uniquement aux causes relatives au mariage.

Dans les collections des années immédiatement successives, parmi lesquelles se démarque le prestigieux recueil des décisions Coram Lega habitae, des années 1909-1914, les demandes de déclaration de nullité et celles de séparation sont dominantes. Si la séparation était le plus souvent demandée par les épouses à cause de sévices souvent associés à la haine mortelle, ${ }^{74} \mathrm{le}$ motif de nullité le plus fréquemment cité était le vice du consentement, souvent encore lié aux choix imposés par la famille, spécialement de l'épouse, même au début du vingtième siècle. ${ }^{75}$ Cependant, les cas d'espèce de non-respect des canons de Trente ne manquaient pas (surtout dans l'identification du curé de la paroisse du domicile) ${ }^{76}$ et aussi la disparité de culte ${ }^{77}$ ou la démence: ${ }^{78}$ dans presque toutes les affaires, la Rote reconnut l'existence du motif de nullité sur base de témoignages concordants ou d'indices sans équivoque. 
Parmi les sentences de nullité, une attention particulière doit être donnée à un cas de simulation soumise à l'attention des juges de la Rote par une jeune épouse parisienne à l'encontre de son mari, ayant une forte inclinaison à l'adultère et au libertinage: l'époux avait déclaré publiquement, à plusieurs occasions, d'épouser les théories socialo-communistes sur la communauté des biens et également les conceptions les plus audaces sur le l'amour libre, et avait admis d'avoir contracté ses lucratives noces religieuses, en plus de son évident intérêt financier, en dépit de son affirmé 'crédo' communiste, également pour la forte attraction envers la jeune femme, "belle, honnête et pudique", qu'il n'aurait pu avoir que comme épouse, alors qu'il désirait, en réalité, l'avoir seulement comme maitresse. ${ }^{79}$

Un élément qui unit ces causes matrimoniales du début du siècle est leur provenance, en grande partie, du contexte français (tout spécialement Paris, Grenoble ou la Suisse française), souvent pour couronner des sentences de divorce déjà obtenues devant le tribunal civil, suite à la réintroduction du divorce en France en 1884, ${ }^{80}$ après la parenthèse de Napoléon Ier.

Dans un scénario similaire, le Code de 1917 n'aura pas l'objectif d'innover, comme d'ailleurs le précisait le can. 6, selon lequel "Codex vigentem huc usque disciplinam plerumque retinet, licet opportunas immutationes afferat". ${ }^{81}$

Les règles du mariage étaient enfermées dans 131 canons, au titre $7^{\circ} \mathrm{du}$ troisième livre, auxquels s'ajoutaient les canons du livre $4^{\circ}$ sur les causes matrimoniales ${ }^{82}$ et quelques autres dispositions éparpillées dans d'autres titres.

Le droit existant était essentiellement réitéré à partir du lien entre le contrat et le sacrement pour les baptisés, défendu fermement depuis des siècles contre les prises de position en faveur de la sécularisation du mariage.

Du décret Ne temere, approuvé par la Congrégation du Concile en 1907, était reprise l'exigence de la documentation écrite pour la validité des fiançailles: ${ }^{83}$ uniquement dans ce cas la rupture injustifiée de la promesse faisait naître l'obligation au dédommagement, quantifié par le tribunal civil ou ecclésiastique. Les indications sur l'âge des fiancés n'étaient pas données et il s'ensuivit un débat doctrinal entre ceux qui, comme le cardinal Gasparri, retenait que la même maturité d'esprit requise pour le mariage était nécessaire pour les fiançailles, et ceux qui, dans le sillage de l'opinion classique, ne reconnaissait pas la même importance à cet engagement. ${ }^{84}$

Pour les noces, l'âge était relevé de quatorze ans à seize pour les garçons et de douze ans à quatorze pour les filles, alors que l'absence de maturité de l'une 
des parties, même après avoir atteint l'âge légal, rendait le mariage invalide à cause de l'empêchement de droit naturel. ${ }^{85}$

Par contre, l'incapacité de procréer constituait un empêchement de droit ecclésiastique et sa persistance, même après avoir atteint l'âge légal, n'avait pas d'incidence sur la validité de l'union. ${ }^{86}$

Toujours à partir du décret Ne temere, la compétence à la célébration du mariage n'était plus l'apanage du curé de la paroisse du domicile, comme cela était requis par le décret Tametsi, mais bien celui du curé du lieu de la célébration, conformément à un critère territorial et non plus personnel. ${ }^{87}$

Bien évidemment, le consentement mutuel du mariage était toujours requis ${ }^{88}$ ce qui rendait les époux ministres du sacrement en présence du curé.

La notion de droit sur le corps était toujours présente, associée aux fins primaires de la procréation. ${ }^{89}$ Le nombre des empêchements était réduit, alors que le dogme de l'indissolubilité était fermement confirmé. ${ }^{90}$ Le mariage valide, mais non consommé, pouvait être dissous grâce au privilège paulin (la dissolution en faveur de la foi du mariage même consommé entre non-baptisés, lorsque l'une des deux personnes se convertissait et se remariait), ${ }^{91}$ grâce à la profession religieuse de l'un des époux ou à la dispense du Siège Apostolique. ${ }^{92}$ La séparation était admise ${ }^{93}$ et l'inobservance des formes requises pour la validité du mariage était sanctionnée avec la nullité. ${ }^{94}$

De cette manière, l'Eglise réaffirmait avec force ses principes et ses valeurs, sans parcourir de nouvelles voies, obligée de se défendre contre la laïcisation de la société, les attaques de l'anticléricalisme et l'irréligiosité croissante, de plus en plus diffuse et présente dans le tissu social, gardienne comme elle l'était (et l'est toujours) d'une tradition millénaire que les nouvelles conceptions avaient - et dans le futur auraient certainement encore - menacée et souvent même ébranlée.

\section{BIBLIOGRAPHIE}

AA.VV. (1985), Violence et violences, Lyon.

AL KALAK, M. (2019), "L'autorità di un concilio. Trento, la sua applicazione e il suo mito", Cristianesimo nella storia, vol. XL, nº 1, pp. 91-111.

ALBERIGO, G. et ROGGER, I. (1997), Il Concilio di Trento nella prospettiva del terzo millennio, Atti del Convegno tenuto a Trento il 25-28 settembre 1995, Brescia. 
ALESSI, G. (1990), "Il gioco degli scambi: seduzione e risarcimento nella casistica cattolica del XVI e XVII secolo", Quaderni storici, vol. 75, pp. 805-831.

ALESSI PALAZZOLO, G. (1979), Prova legale e pena. La crisi del sistema tra evo medio e moderno, Napoli.

ANTONUCCI, M. (édité par) (1974), L'età della Controriforma in Italia, Roma.

AZNAR GIL, F. R. (1989), La institución matrimonial en la Hispania cristiana bajo-medieval (1215-1563), Salamanca.

BASDEVANT-GAUDEMET, B. (2014), Histoire du droit canonique et des institutions de l'Église latine $X V-X X$ siècle, Paris.

BEDOUELLE, G. (2003), La riforma del cattolicesimo (1480-1620), trad. it. B. Rima, Milano.

BELLAVISTA, G. (1971), “Indizi”, dans Enciclopedia del diritto, 21, Milano, pp. 224-232.

BELLIGNI, E. (2018), Voci di riforma. Renovatio e concilio prima e dopo il Tridentino, Milano.

BERNHARD, J. (1980), "Le décret Tametsi du concile de Trente; triomphe $\mathrm{du}$ consensualisme matrimonial ou institution de la forme solennelle du mariage?", Revue de droit canonique, vol. XXX (= Etudes offerts a J. Gaudemet), pp. 209-234.

BERNHARD, J., LEFEBVRE, C. et RAPP, F. (1990), L'époque de la Réforme et du Concile de Trente. Histoire du Droit et des Institutions de l'Église en Occident, 14, Paris.

BERNINO, D. (1717), Il tribunale della S. Romana Rota, Roma.

BIANCHEDI, C. (1927), "Violenza carnale", dans Digesto Italiano, 24, Torino, col. 1064-1135.

BIROCCHI, I. et FABBRICATORE, E. (2013), "De Luca, Giovanni Battista", dans BIROCCHI, I., CORTESE, E., MATTONE, A. et MILETTI, M. N. (édité par), Dizionario biografico dei giuristi italiani (XII-XX secolo), I, Bologna.

BOSSY, J. (1985), Christianity in the West 1400-1700, Oxford.

BRANDILEONE, F. (1906), "La celebrazione del matrimonio in Roma nel secolo XV ed il Concilio di Trento" e "Per la storia dei riti nuziali in Italia dans" dans BRANDILEONE, F., Saggi sulla storia della celebrazione del matrimonio in Italia, Milano, pp. 291-340, 489-499. 
BRUNDAGE, J. A. (1987), Law, Sex and Christian Society in Medieval Europe, Chicago and London.

BRUNDAGE, J. A. (1993), "Concubinage and Marriage in Medieval Canon Law", dans BRUNDAGE, J. A., Sex, Law and Marriage in the Middle Ages, Great Yarmouth.

BRUNDAGE, J. A. (1993), "Marriage and Sexuality in the Decretals of Pope Alexander III", dans BRUNDAGE, J. A., Sex, Law and Marriage in the Middle Ages, Great Yarmouth.

CALISSE, C. (1941), Principii di diritto penale nei giuristi del rinascimento (sec. XIII-XVI), Milano.

CAVANNA, A. (1975), La codificazione penale in Italia. Le origini lombarde, Milano.

CAVINA, M. (2007), Il padre spodestato. L'autorità paterna dall'antichità a oggi, Roma-Bari.

CAZZETTA, G. (1999), Praesumitur seducta. Onestà e consenso femminile nella cultura giuridica moderna, Milano.

CERCHIARI, E. (1921), Capellani Papae et Apostolicae Sedis auditores causarum Sacri Palatii Apostolici seu Sacra Rota Romana ab origine ad diem usque 20 septembris 1870. Relatio historica-iuridica, Roma.

COCCHIARA, M. A. (édité par) (2014), Violenza di genere, politica e istituzioni, Milano.

CONDE CID, J. C. (2014), "L’origine del privilegio paolino", Ius Ecclesiae. Rivista internazionale di diritto canonico, vol. XXVI, $\mathrm{n}^{\circ} 2$

CORDERO, F. (1986), Criminalia. Nascita dei sistemi penali, Roma-Bari.

COZZI, G. (1983), "Padri, figli e matrimoni clandestini", dans MANOUKIAN, A. (édité par), I vincoli familiari in Italia. Dal secolo XI al secolo XX, Bologna.

COZZI, G. (1985-1986), Il dibattito sui matrimoni clandestini.Vicende giuridiche, sociali, religiose dell'istituzione matrimoniale tra Medio Evo ed Età moderna, dispensa universitaria, Anno accademico 1985-1986.

CRISTIANI, L. (1977), La Chiesa al tempo del Concilio di Trento .Storia della Chiesa, 17), édité par A. Galuzzi, Torino.

DAUVILLIER, J. (1933), Le mariage dans le droit canonique de l'èglise depuis le Décret de Gratien (1140) jusqu'à la mort de Clément V (1314), Paris.

DE LUCA, G. B. (1680), Il Principe cristiano pratico, Roma.

DEL RE, N. (1970), La Curia Romana. Lineamenti storico-giuridici, Roma. 
DELLA ROCCA, F. (1973), “Tribunali ecclesiastici”, dans Novissimo Digesto Italiano, XIX, pp. 753-761.

DEZZA, E. (1992), Tommaso Nani e la dottrina dell'indizio nell'età dei lumi, Milano.

DI RENZO VILLATA, G. (1989), "Separazione personale (storia)", dans Enciclopedia del diritto, 41, Milano, pp. 1350-1376.

DI RENZO VILLATA, G. (1995), "Persone e famiglia nel diritto medievale e moderno", dans Digesto delle discipline privatistiche. Sezione civile, XIII, Torino, pp. 457-526.

DOLEZALEK, G. et NÖRR, K. W. (1973), "Die Rechtsprechungssammlungen der mittelalterlichen Rota", Handbuch der Quellen und Literatur der neueren europäischen Privatrechtsgeschichte, 1, Mittelalter (1100-1500), München.

DOLEZALEK, G. et NÖRR, K. W. (1975), "Ein Kapitel aus der Geschichte der Rechtsprechung: Die Rota Romana", Ius Commune, vol. 5, pp. 192-209.

DONAHUE, C. (1995), "Was there a change in marriage law in the late Middle Ages?", Rivista internazionale di diritto comune, VI.

DUBY, G. (1978), Medieval marriage. Two models from twelfth-Century France, Baltimore and London.

ERMINI, G. (1936), "La giurisprudenza della Rota Romana come fattore costitutivo dello Ius Commune", dans Studi in onore di F. Scaduto, I, Firenze.

ERRERA, A. (2003), "La procedura dei tribunali ecclesiastici in materia matrimoniale: cenni di un'evoluzione storica", dans PADOA SCHIOPPA, A., DI RENZO VILLATA, G. et MASSETTO, G. P. (édité par), Amicitiae pignus. Studi in ricordo di Adriano Cavanna, II, Milano, pp. 966-995.

ESMEIN, A. (1935), Le mariage en droit canonique, II, Paris.

ESPOSITO, A., FRANCESCHI, F. et PICCINNI, G. (édité par) (2018), Violenza alle donne: una prospettiva medievale, Bologna.

FANTAPPIÉ, C. (2011), Storia del diritto canonico e delle istituzioni della Chiesa, Bologna.

FANTAPPIÉ, C. (2017), "El Código de derecho canónico de 1917 y su repercusión en la vida de la Iglesia", Separata 'Ius communionis', vol 5, cuad. 2, Universidad San Dámaso, pp. 209-224.

FARINACCIUS, P. (1613), Praxis et theorica criminalis pars quarta, Lugduni 
FATA, M., FORGÇ, A., HAUG-MORITZ, G. et SCHINDLING, A. (édité par) (2019), Das Trienter Konzil un seine Rezeption im Ungarre des 16. und 17. Jahrhunderts, Münster.

FECI, S. et SCHETTINI, L. (édité par) (2017), La violenza contro le donne nella storia: contesti, linguaggi, politiche del diritto (secoli XV-XXI), Roma.

FIORELLI, P. (1953), La tortura giudiziaria nel diritto comune, I, Milano.

FRANÇOIS, W. et SOEN, V. (edité par) (2018), The Council of Trent: Reform and Controversy in Europe and Beyond (1545-1700), vol. 1, Between Trent, Rome and Wittenberg, Göttingen.

GABRIELI, F. (1939), "Ratto", dans Novissimo Digesto Italiano, 10, Torino, col. 1122-1138.

GABRIELI, F. (1940), "Violenza carnale", dans Novissimo Digesto Italiano, 22/2, Torino, col. 1069-1079.

GARCÍA HOURCADE, J. J. (2015), "Trento: negociación y discernimento", Vergentis. Revista de Investigación de la Cátedra Internacional Conjunta Inocencio III, $\mathrm{n}^{\mathrm{o}}$ 1, pp. 215-254.

GAUDEMET, J. (1980), "Il legame matrimoniale nel XVII secolo. Legislazione canonica e tendenze laiche", dans BUONANNO, M. (édité par), Le funzioni sociali del matrimonio. Modelli e regole della scelta del coniuge dal XIV al XX secolo, Milano.

GAUDEMET, J. (1987), Le mariage en occident. Les moeurs et le droit, Paris (trad. it. Il matrimonio in occidente, Torino 1989).

GAUDEMET, J. (1994), Eglise et cité. Histoire du droit canonique, Paris.

GILLES, H. (1955), "Gilles Bellemère et le tribunal de la Rote à la fin du XIV siècle”, Mélanges d'archéologie et d'histoire, vol. 65, pp. 281-319.

GILLES, H. (1955), "Les auditeurs de Rote au temps de Clement VII et Benoît XIII (1378-1417). Notes biographiques", Mélanges d'archéologie et d'histoire, vol. 65, pp. 321-337.

GISMONDI, P. (1949), "La celebrazione del matrimonio secondo la dottrina e la legislazione canonica sino al Concilio tridentino", Ephemerides Iuris canonici, V, pp. 3-40.

GÖLLER, E. (1911), "Zur Geschichte der Romana Rota", Archiv für katholisches Kirchenrecht, vol. 91, pp. 19-48.

GRAZIOLI, M. (1911-1915), "Ratto", dans Digesto Italiano, 20/1, Torino, col. 172-195.

GUILLEMAIN, B. (1952), "Les chapelains d'honneur des papes d'Avignon", Mélanges d'archéologie et d'histoire, vol. 64, pp. 217-238. 
GUILLEMAIN, B. (1962), La cour pontificale d'Avignon (1309-1376). Etude d'une société, Paris.

HOBERG, H. (1954), "Die Rotarichter in den Eidregister der Apostolischen Kammer von 1347 bis 1494", Quellen und Forschungen aus italienischen Archiven und Bibliotheken, vol. 34, pp. 159-172.

ISERLOH, E., GLAZIK, J. et JEDIN, H. (1993) Riforma e Controriforma. Crisi, consolidamento, diffusione missionaria XVI-XVII sec. Storia della Chiesa, 4, trad. it., Milano.

JANKOWIAK, E. (2007), La Curie romaine de Pie IX à Pie X, Roma. JEDIN, H. (1973-1982), Storia del Concilio di Trento, 4 voll., Brescia.

JEDIN, H. et PRODI, P. (édité par) (1979), Il Concilio di Trento come crocevia della politica europea, Bologna.

JEMOLO, A. C. (1941), Il matrimonio nel diritto canonico, Milano.

KLAPISCH-ZUBER, Ch. (1988), "Zaccaria, o il padre spodestato. I riti nuziali in Toscana tra Giotto e il Concilio di Trento", dans KLAPISCH-ZUBER, Ch., La famiglia e le donne nel Rinascimento a Firenze, Roma-Bari.

LE BRAS, G. (1927), "Mariage”, dans Dictionnaire de théologie catholique, Paris, coll. 2123-2223.

LE BRAS, G. (1959), "Institutions ecclésiastiques de la Chrétienté médiévale", dans Histoire de l'Eglise depuis les origines jusqu'à nos jours, XII, Tournai.

Le droit de la famille en Europe. Son évolution depuis l'antiquité jusqu'à nos jours (1992), Actes des Journées internationales d'histoire du droit, Strasbourg.

LEFEBVRE, C. (1938), Les pouvoirs du juge en droit canonique, Paris.

LEFEBVRE, C. (1965), "Rote Romaine", dans Dictionnaire de droit canonique, VII, Paris, pp. 742-770.

LEGA, M. (1912), "Praefazione" a S. Romanae Rotae decisiones seu sententiae, Roma, ensuite dans Coram Lega habitae S. R. Rotae decisiones, Roma, 1926.

LETTMANN, R. (1967), Die Diskussion über die klandestinen Ehen und die Einführung einer zur Gültigkeitverplichtenden Eheschliessungsform auf dem Konzil von Trient: Eine kanonistische Untersuchung, Münster (Münsterische Beiträgezur Theologie, vol. 51).

LOMBARDI, D. (1996), "Fidanzamenti e matrimoni dal Concilio di Trento alle riforme settecentesche", dans DE GIORGIO, M. et KLAPISCHZUBER, Ch. (édité par), Storia del matrimonio, Roma-Bari. 
LOMBARDI, D. (2001), Matrimoni di antico regime, Bologna (Annali dell'Istituto storico italo-germanico in Trento. Monografie, 34).

LOMBARDI, D. (2008), Storia del matrimonio. Dal Medioevo a oggi, Bologna.

LONGO, M. (1975), "Vis”, dans Novissimo Digesto italiano, 20, Torino, col. 989-994.

MANZONI, A. (1840), I promessi sposi, Milano

MARCHETTI, P. (1994), Testis contra se. L'imputato come fonte di prova nel processo penale dell'età moderna, Milano.

MARCHETTO, G. (2008), Il divorzio imperfetto. I giuristi medievali e la separazione dei coniugi, Bologna.

MARCHISELLO, A. (2002), "Il matrimonio post-tridentino nelle 'Annotationes Practicae ad Sacrum Concilium Tridentinum' (1672) di Giovanni Battista De Luca", Annali dell'Istituto storico italo-germanico, vol. 28.

MARCOCCHI, M., SCARPATI, C., ACERBI, A. et ALBERIGO, G. (1997), Il Concilio di Trento. Istanze di riforma e aspetti dottrinali, Milano.

MARONGIU, A. (1984), "Matrimonio medievale e matrimonio postmedievale. Spunti storico-critici”, Rivista di storia del diritto italiano, vol. LVII, pp. 101-119.

MARTINA, G. (1988), La Chiesa nell'età della riforma, Brescia.

MASSETTO, G. P. (1987), "Ratto (dir. interm.)", dans Enciclopedia del diritto, 38, Milano, pp. 725-743.

MASSETTO, G. P. (1994), "La prassi giuridica lombarda nell'opera di Giulio Claro (1525-1575)", dans Saggi di storia del diritto penale lombardo (Secc. XVI-XVIII), Milano, pp. 11-59.

MASSETTO, G. P. (1994), "I reati nell'opera di Giulio Claro", dans Saggi di storia del diritto penale lombardo, Milano, pp. 61-227.

MAZZACANE, A. (1990), "De Luca, Giovanni Battista", dans Dizionario biografico degli italiani, XXXVIII, Roma.

MAZZANTI, G. (2020), Matrimoni post-tridentini. Un dibattito dottrinale fra continuità e cambiamento (secc. XVI-XVIII), Bologna.

MECCARELLI, M. (1998), Arbitrium. Un aspetto sistematico degli ordinamenti giuridici in età di diritto comune, Milano.

MEGNA, L. (1985), "In margine ad alcune carte processuali di area vicentina: sponsali e matrimonio tra XVI e XVII secolo", dans POVOLO, C. (édité 
par), Bolzano Vicentino. Dimensione del sociale e vita economica in un villaggio della pianura vicentina (secoli XIV-XIX), Bolzano Vicentino.

MINNUCCI, V. G. (2020), "'Viro quaenam castigatio in uxorem permittatur'. La separazione fra coniugi ex saevitia in una decisione giudiziale dell'età moderna", dans SANTANGELO CORDANI, A. et ZICCARDI, G. (édité par), Tra odio e (dis)amore. Violenza di genere e violenza sui minori dalla prospettiva storica all'era digitale, Collana Università degli Studi di Milano, Facoltà di Giurisprudenza, Pubblicazioni del Centro di Studi sulla Giustizia, Milano, pp. 19-42.

MOLLAT, G. (1920), Les papes d'Avignon, Paris.

MONETA, P. (1989), "Rota Romana (tribunale della)", dans Enciclopedia del diritto, 41, Milano, pp. 137-151.

MORONI, G. (1857), "Uditori di Rota e Tribunale della Sacra Rota Romana", dans Dizionario di erudizione storico-ecclesiastica, vol. LXXXII, pp. 206-278.

NAZ, R. (1965), "Rapt", dans Dictionnaire de droit canonique, 7, Paris, pp. 454-460.

NUZZO, L. (1998), "Il matrimonio clandestino nella dottrina canonistica del basso medioevo", Studia et Documenta Historiae et Iuris, vol. 64, pp. 351-396.

O'MALLEY, J. W. (2000), Trent and All That. Renaming Catholicism in the Early Modern Era, Cambridge Mass.-London [trad. it. Trento e dintorni. Per una nuova definizione del cattolicesimo nell'età moderna, édité par M. Fantoni, Roma 2004].

O'MALLEY, J. W. (2013), Trent. What Happened at the Council, Cambridge Mass [trad. it. Trento. Il racconto del Concilio, trad. it. S. Galli, Milano 2013].

OURLIAC, P. et DE MALAFOSSE, J. (1968), Histoire du droit privé, Paris.

PADOVANI, T. (1989), “Costringimento fisico e psichico”, dans Digesto delle discipline penalistiche, 3 , Torino.

PETOT, P. (1992), Histoire du droit privé français. La famille, Paris.

PEYRONEL RAMBALDI, S. (1984), Il Concilio di Trento, Milano.

PO-CHIA HSIA, R. (2001), La Controriforma. Il mondo del rinnovamento cattolico (1540-1700), trad. it. E. Bonora, Bologna.

PRODI, P. (1989), "Il matrimonio tridentino e il problema dei figli illegittimi", dans Per Giuseppe Sebesta: scritti e nota bio-bibliografica per 
il settantesimo compleanno, a cura della Biblioteca Comunale di Trento, Trento.

PRODI, P. (2000), Una storia della giustizia. Dal pluralismo dei fori al moderno dualismo tra coscienza e diritto, Bologna.

PRODI, P. (2010), Il paradigma tridentino. Un'epoca della storia della Chiesa, Brescia.

PRODI, P. et REINHARD, W. (édité par) (1996), Il Concilio di Trento e il moderno, Bologna.

PROSPERI, A. (2001), Il Concilio di Trento: una introduzione storica, Torino.

PROSPERI, A. (2015), "La Chiesa di Roma: il papato e la riforma tridentina nel Cinquecento", dans LAVENIA, V. (édité par), Storia del cristianesimo, vol. III, L'età moderna (secoli XVI-XVIII), Roma, pp. 183-212.

QUAGLIONI, D. (2001), "“Sacramenti detestabili'. La forma del matrimonio prima e dopo Trento, dans SEIDEL MENCHI, S. et QUAGLIONI, D. (édité par), Matrimoni in dubbio. Unioni controverse e nozze clandestine in Italia dal XIV al XVIII secolo, Bologna (Annali dell'Istituto storico italogermanico in Trento. Quaderni, 57).

RASI, P. (1941), “L'applicazione delle norme del concilio di Trento in materia matrimoniale", dans Studi di storia e diritto in onore di Arrigo Solmi, Milano, I.

RASI, P. (1943), "La conclusione del matrimonio prima del Concilio di Trento", Rivista di storia del diritto italiano, vol. XVI, pp. 233-321.

RASI, A. (1949), "La separatio thori e le norme del Concilio di Trento", Rivista di storia del diritto italiano, 21.

RASI, P. (1958), La conclusione del matrimonio nella dottrina prima del Concilio di Trento, Napoli.

RAYNAUD, C. (1991), La violence au moyen âge (XIII-XIV siècle), Paris.

ROBERTI, F. (1956), De processibus, I, Città del Vaticano.

ROBERTI, F. (1940), “Tribunali ecclesiastici”, dans Nuovo Digesto Italiano, vol. XII, no 2 , pp. 517-525.

ROBERTI, M. (1932), Svolgimento storico della famiglia italiana, Milano.

ROBERTI, M. (1935), Svolgimento storico del diritto privato in Italia, III, La famiglia, Padova.

ROSONI, I. (1993), "Violenza (dir. interm.)", dans Enciclopedia del diritto, 46, Milano, pp. 843-858.

ROSONI, I. (1995), Quae singula non prosunt collecta iuvant. La teoria della prova indiziaria nell'età medievale e moderna, Milano. 
SÁNCHEZ, T. (1612), Disputationum de sancto matrimonii sacramento libri decem, Venetiis, lib. VII, disp. XII, n. 41

SANTANGELO CORDANI, A. (2001), La giurisprudenza della Rota Romana nel secolo XIV, Milano.

SANTANGELO CORDANI, A. (2011), "Vis grata puellis. Bonnes moeurs et violence sexuelle dans la Praxis et theorica criminalis de Prospero Farinacci", dans CHAMOCHO, M. A. (édité par), Droit et moeurs. Implication et influence des moeurs dans la configuration du droit. Actes des Journées internationales de la Société d'histoire du droit, Jaén-Baeza, 3-6 juin 2010, Jaén, Universidad de Jaén, pp. 319-332.

SANTANGELO CORDANI, A. (2018), "Intestate Succession Between Doctrine and Roman Rota Case Law in the Sixteenth and Seventeenth Centuries", dans DI RENZO VILLATA, G. (édité par), Succession Law, Practice and Society in Europe across the Centuries, Heidelberg, Springer, pp. 549-566.

SCHIAPPOLI, D. (1905), Diritto penale canonico, Milano.

SCHOTT, H. (1954), "Luthers Stellung zur Ehe", Zeitschrift fürsystematisch Theologie.

SEIDEL MENCHI, S. (2001), "Percorsi variegati, percorsi obbligati. Elogio del matrimonio pre- tridentino", dans SEIDEL MENCHI, S. et QUAGLIONI, D. (édité par), Matrimoni in dubbio. Unioni controverse e nozze clandestine in Italia dal XIV al XVIII secolo", Bologna (Annali dell'Istituto storico italo-germanico in Trento. Quaderni, 57).

SEIDEL MENCHI, S. et QUAGLIONI, D. (édité par) (2004), Trasgressioni. Seduzione, concubinato, adulterio, bigamia (XIV-XVIII secolo), Bologna.

SPINELLI, L. (1992), “Tribunali ecclesiastici”, dans Enciclopedia del diritto, vol. 45 , pp. 69-80.

TALLON, A. (2004), Il concilio di Trento, trad. it. B. Pistocchi, Cinisello Balsamo.

TAMASSIA, N. (1910), La famiglia italiana nei secoli decimoquinto e decimo sesto, Milano, Palermo, Napoli.

TAMASSIA, N. (1911), La famiglia italiana nei secoli decimoquinto e decimosesto, Palermo.

TOMASELLI, S. et PORTER, R. (édité par) (1986), Rape. An historical and cultural Enquiry, Oxford.

TORELLI, P. (1947), Lezioni di storia del diritto italiano. Diritto privato. La famiglia, Milano. 
VACCARI, P. (1970), "Separazione personale dei coniugi (Storia del diritto)", dans Novissimo Digesto italiano, XVII, Torino.

VALSECCHI, C. (1999), "Causa matrimonialis est gravis et ardua'. Consiliatores e matrimonio fino al Concilio di Trento", dans Studi di Storia del diritto, II, Milano, pp. 407-580.

ZARRI, G. (1996), "Il matrimonio tridentino", dans PRODI, P. et REINHARD, W. (édité par), Il Concilio di Trento e il moderno, Bologna.

\section{NOTES}

1 Angela Santangelo Cordani es Catedrática de Historia del Derecho de la Universidad degli Studi de Milán.

$2 \quad$ Sur le Concile de Trente (1545-1563) l'historiographie est exterminée. Il suffise de rappeler ici, sans prétendre être complet, JEDIN, H. (1973-1982), Storia del Concilio di Trento, 4 voll., Brescia; ANTONUCCI, M. (édité par) (1974), L'età della Controriforma in Italia, Roma; CRISTIANI, L. (1977), La Chiesa al tempo del Concilio di Trento (Storia della Chiesa, 17), édité par A. Galuzzi, Torino; JEDIN, H. et PRODI, P. (édité par) (1979), Il Concilio di Trento come crocevia della politica europea, Bologna; PEYRONEL RAMBALDI, S. (1984), Il Concilio di Trento, Milano; MARTINA, G. (1988), La Chiesa nell'età della riforma, Brescia; BERNHARD, J., LEFEBVRE, C. et RAPP, F. (1990), L'époque de la Réforme et du Concile de Trente (Histoire du Droit et des Institutions de l'Église en Occident, 14), Paris; ISERLOH, E., GLAZIK, J. et JEDIN, H. (1993), Riforma e Controriforma. Crisi, consolidamento, diffusione missionaria XVI-XVII sec. (Storia della Chiesa, 4), trad. it., Milano; PRODI, P. et REINHARD, W. (édité par) (1996), Il Concilio di Trento e il moderno, Bologna; ALBERIGO, G. et ROGGER, I. (1997), Il Concilio di Trento nella prospettiva del terzo millennio, Atti del Convegno tenuto a Trento il 25-28 settembre 1995, Brescia; MARCOCCHI, M., SCARPATI, C., ACERBI, A. et ALBERIGO, G. (1997), Il Concilio di Trento. Istanze di riforma e aspetti dottrinali, Milano; O’MALLEY, J. W. (2000), Trent and All That. Renaming Catholicism in the Early Modern Era, Cambridge Mass.-London [trad. it. Trento e dintorni. Per una nuova definizione del cattolicesimo nell'età moderna, édité par M. Fantoni, Roma 2004]; O’MALLEY, J. W. (2013), Trent. What Happened at the Council, Cambridge Mass. [trad. it. Trento. Il racconto del Concilio, trad. it. S. Galli, Milano 2013]; PRODI, P. (2000), Una storia della giustizia. Dal pluralismo dei fori al moderno dualismo tra coscienza e diritto, Bologna, pp. 269-324; PRODI, P. (2010), Il paradigma tridentino. Un'epoca della storia della Chiesa, Brescia; POCHIA HSIA, R. (2001), La Controriforma. Il mondo del rinnovamento cattolico (1540-1700), trad. it. E. Bonora, Bologna, pp. 19-38; PROSPERI, A. (2001), Il Concilio di Trento: una introduzione storica, Torino; PROSPERI, A. (2015), "La Chiesa di Roma: il papato e la riforma tridentina nel Cinquecento", dans LAVENIA, V. (édité par), Storia del cristianesimo, vol. III, L'età moderna (secoli XVI-XVIII), Roma, pp. 183-212; BEDOUELLE, G. (2003), La riforma del cattolicesimo (1480-1620), trad. it. B. Rima, Milano; TALLON, A. (2004), Il concilio di Trento, trad. it. B. Pistocchi, Cinisello Balsamo; BASDEVANT-GAUDEMET, B. (2014), Histoire du droit canonique et des institutions de l'Église latine XVe-XXe siècle, Paris, pp. 39-54; GARCÍA HOURCADE, J. J. (2015), “Trento: negociación y discernimento", Vergentis. Revista de Investigación de la Cátedra Internacional Conjunta Inocencio III, $\mathrm{n}^{\circ}$ 1, pp. 215-254; BELLIGNI, E. (2018), Voci di riforma. Renovatio e concilio prima e dopo il Tridentino, Milano; FRANÇOIS, W. et SOEN, V. (edité par) (2018), The Council of Trent: Reform and Controversy in Europe and Beyond (1545-1700), vol. 1, Between Trent, Rome and Wittenberg, Göttingen; AL KALAK, M. (2019), "L'autorità di un concilio. Trento, la sua applicazione e il suo mito", Cristianesimo nella storia, vol. XL, n 1, pp. 91-111; FATA, M., FORGÇ, A., HAUG-MORITZ,

Revista de Estudios Jurídicos, UJAEN, España $\mid$ AÑO 2021 |NUM. 21, e6775 | ISSN 1576-124X 
G. et SCHINDLING, A. (édité par) (2019), Das Trienter Konzil un seine Rezeption im Ungarre des 16. und 17. Jahrhunderts, Münster.

3 Les origines et l'histoire de la Rote romaine ont fait l'objet d'innombrables recherches par l'historiographie juridique italienne et étrangère; les principales contributions auxquelles il est essentiel de se référer sont: BERNINO, D. (1717), Il tribunale della S. Romana Rota, Roma; MORONI, G. (1857), "Uditori di Rota e Tribunale della Sacra Rota Romana", dans Dizionario di erudizione storico-ecclesiastica, vol. LXXXII, pp. 206-278; GÖLLER, E. (1911), "Zur Geschichte der Romana Rota", Archiv für katholisches Kirchenrecht, vol. 91, pp. 19-48; LEGA, M. (1912), "Praefazione" a S. Romanae Rotae decisiones seu sententiae, Roma, ensuite dans Coram Lega habitae S. R. Rotae decisiones, Roma, 1926; MOLLAT, G. (1920), Les papes d'Avignon, Paris, pp. 332 ss.; CERCHIARI, E. (1921), Capellani Papae et Apostolicae Sedis auditores causarum Sacri Palatii Apostolici seu Sacra Rota Romana ab origine ad diem usque 20 septembris 1870. Relatio historica-iuridica, Roma; ERMINI, G. (1936), "La giurisprudenza della Rota Romana come fattore costitutivo dello Ius Commune", dans Studi in onore di F. Scaduto, I, Firenze, pp. 284-297; LEFEBVRE, C. (1938), Les pouvoirs du juge en droit canonique, Paris, pp. 247-255; ROBERTI, F. (1940), “Tribunali ecclesiastici", dans Nuovo Digesto Italiano, vol. XII, $\mathrm{n}^{\circ}$ 2, pp. 517-525, en particulier pp. 517-519; GUILLEMAIN, B. (1952), "Les chapelains d'honneur des papes d'Avignon", Mélanges d'archéologie et d'histoire, vol. 64, pp. 217-238; HOBERG, H. (1954), "Die Rotarichter in den Eidregister der Apostolischen Kammer von 1347 bis 1494", Quellen und Forschungen aus italienischen Archiven und Bibliotheken, vol. 34, pp. 159-172; GILLES, H. (1955), "Gilles Bellemère et le tribunal de la Rote à la fin du XIV siècle", Mélanges d'archéologie et d'histoire, vol. 65, pp. 281-319; GILLES, H. (1955), "Les auditeurs de Rote au temps de Clement VII et Benoît XIII (1378-1417). Notes biographiques”, Mélanges d'archéologie et d'histoire, vol. 65, pp. 321-337; ROBERTI, F. (1956), De processibus, I, Città del Vaticano, pp. 335 ss.; LE BRAS, G. (1959), "Institutions ecclésiastiques de la Chrétienté médiévale", dans Histoire de l'Eglise depuis les origines jusqu'à nos jours, XII, Tournai, pp. 355-357; GUILLEMAIN, B. (1962), La cour pontificale d'Avignon (1309-1376). Etude d'une société, Paris, pp. 55 e 345-356; LEFEBVRE, C. (1965), "Rote Romaine", dans Dictionnaire de droit canonique, VII, Paris, pp. 742-770; DEL RE, N. (1970), La Curia Romana. Lineamenti storico-giuridici, Roma, pp. 243-254; DOLEZALEK, G. et NÖRR, K. W. (1973), "Die Rechtsprechungssammlungen der mittelalterlichen Rota", Handbuch der Quellen und Literatur der neueren europäischen Privatrechtsgeschichte, 1, Mittelalter (1100-1500), München, pp. 849-850; DOLEZALEK, G. et NÖRR, K. W. (1975), "Ein Kapitel aus der Geschichte der Rechtsprechung: Die Rota Romana”, Ius Commune, vol. 5, pp. 192-209; DELLA ROCCA, F. (1973), “Tribunali ecclesiastici", dans Novissimo Digesto Italiano, XIX, pp. 753-761, en particulier pp. 755-757; MONETA, P. (1989), "Rota Romana (tribunale della)", dans Enciclopedia del diritto, 41, Milano, pp. 137-151, surtout pp. 148-149; SPINELLI, L. (1992), “Tribunali ecclesiastici”, dans Enciclopedia del diritto, vol. 45, pp. 69-80, en particulier pp. 77-79; GAUDEMET, J. (1994), Eglise et cité. Histoire du droit canonique, Paris, p. 373. Enfin je rappelle SANTANGELO CORDANI, A. (2001), La giurisprudenza della Rota Romana nel secolo XIV, Milano; SANTANGELO CORDANI, A. (2018), "Intestate Succession Between Doctrine and Roman Rota Case Law in the Sixteenth and Seventeenth Centuries", dans DI RENZO VILLATA, G. (édité par), Succession Law, Practice and Society in Europe across the Centuries, Heidelberg, Springer, pp. 549-566.

4 "Si quis dixerit, Sacramenta novae legis non fuisse omnia a Jesu Christo Domino nostro instituta, aut esse plura, vel pauciora, quam septem, videlicet: Baptismum, Confirmationem, Eucharestiam, Poenitentiam, Extremam Unctionem, Ordinem et Matrimonium, aut etiam aliquod horum septem non esse vere, et proprie Sacramentum; anathema fit" (Sacrosanctum Concilium Tridentinum, Decretum de Sacramentis, can I, ed. Bassani 1743, p.48).

5 "Tametsi dubitandum non est, clandestina matrimonia, libero contrahentium consensu facta, rata et vera esse matrimonia, quamdiu Ecclesia ea irrita non fecit, et proinde iure damnandi sintilli, ut eos sancta Synodus anathemate damnat, qui ea vera ac rata esse negant, quique falso affirmant, matrimonia a filiis familias sine consensu parentum contracta irrita esse, et parentes ea rata vel irrita facere posse: nihilominus sancta Dei Ecclesia ex iustissimis causis illa 
semper detestata est atque prohibuit" (Sacrosanctum Concilium Tridentinum cit., Decretum de reformatione matrimonii, Caput I, pp. 197-200).

6 Reste toujours fondamentale l'oeuvre de ESMEIN, A. (1935), Le mariage en droit canonique, II, Paris, pp. 163 ss. V. aussi RASI, P. (1941), "L'applicazione delle norme del concilio di Trento in materia matrimoniale", dans Studi di storia e diritto in onore di Arrigo Solmi, Milano, I, pp. 240-241; LETTMANN, R. (1967), Die Diskussion über die klandestinen Ehen und die Einführung einer zur Gültigkeitverplichtenden Eheschliessungsform auf dem Konzil von Trient: Eine kanonistische Untersuchung, Münster (Münsterische Beiträgezur Theologie, vol. 51); BERNHARD, J. (1980), "Le décret Tametsi du concile de Trente; triomphe du consensualisme matrimonial ou institution de la forme solennelle du mariage?", Revue de droit canonique, vol. XXX (= Etudes offerts a J. Gaudemet), pp. 209-234; JEDIN, H. (1973), Storia del concilio di Trento, Brescia, III, pp. 199-226; Brescia 1981, IV/2, pp. 139-173, 201-234; LOMBARDI, D. (2001), Matrimoni di antico regime, Bologna (Annali dell'Istituto storico italo-germanico in Trento. Monografie, 34), pp. 99-126; MARCHISELLO, A. (2002), "Il matrimonio posttridentino nelle 'Annotationes Practicae ad Sacrum Concilium Tridentinum' (1672) di Giovanni Battista De Luca”, Annali dell'Istituto storico italo-germanico, vol. 28; MAZZANTI, G. (2020), Matrimoni post-tridentini. Un dibattito dottrinale fra continuità e cambiamento (secc. XVIXVIII), Bologna.

7 V. ESMEIN, (1935), II, pp. 295 ss.; JEMOLO, A. C. (1941), Il matrimonio nel diritto canonico, Milano, pp. 13 ss.; SCHOTT, H. (1954), "Luthers Stellung zur Ehe", Zeitschrift fürsystematisch Theologie, pp. 33 ss.; NUZZO, L. (1998), "Il matrimonio clandestino nella dottrina canonistica del basso medioevo", Studia et Documenta Historiae et Iuris, vol. 64, pp. 351-396.

8 V. essentiellement ESMEIN, (1935), I, pp. 95 ss.; LE BRAS, G. (1927), "Mariage", dans Dictionnaire de théologie catholique, Paris, coll. 2123-2223; DAUVILLIER, J. (1933), Le mariage dans le droit canonique de l'èglise depuis le Décret de Gratien (1140) jusqu'à la mort de Clément V (1314), Paris. Plus récemment v. DUBY, G. (1978), Medieval marriage. Two models from twelfth-Century France, Baltimore and London; MARONGIU, A. (1984), "Matrimonio medievale e matrimonio postmedievale. Spunti storico-critici", Rivista di storia del diritto italiano, vol. LVII, pp. 101-119; BOSSY, J. (1985), Christianity in the West 1400-1700, Oxford, p. 25 ss.; COZZI, G. (1985-1986), Il dibattito sui matrimoni clandestini. Vicende giuridiche, sociali, religiose dell'istituzione matrimoniale tra Medio Evo ed Età moderna, dispensa universitaria, Anno accademico 1985-1986, pp. 93-159; GAUDEMET, J. (1987), Le mariage en occident. Les moeurs et le droit, Paris (trad. it. Il matrimonio in occidente, Torino 1989); VALSECCHI, C. (1999), "Causa matrimonialis est gravis et ardua'. Consiliatores e matrimonio fino al Concilio di Trento", dans Studi di Storia del diritto, II, Milano, pp. 407-580; SEIDEL MENCHI, S. (2001), "Percorsi variegati, percorsi obbligati. Elogio del matrimonio pre- tridentino" et QUAGLIONI, D. “'Sacramenti detestabili'. La forma del matrimonio prima e dopo Trento, dans SEIDEL MENCHI, S. et QUAGLIONI, D. (édité par), Matrimoni in dubbio. Unioni controverse e nozze clandestine in Italia dal XIV al XVIII secolo, Bologna (Annali dell'Istituto storico italo-germanico in Trento. Quaderni, 57), pp. 52-53 et 75-79; PROSPERI, (2001), pp. 134-137.

9 Voir par exemple Sacrae Rotae Romanae Decisionum Novissimarum..., I, Romae 1642, dec. 264, n. 37 et dec. 316, n. 28; Sacrae Rotae Romanae decisionum Recentiorum..., V/1, Romae 1642, dec. 264, nn. 24-28; Sacrae Rotae Romanae decisionum Recentiorum..., V/1, Romae 1642, dec. 264, nn. 24 ss.; Decisiones Sacrae Rotae Romanae Coram R.P.D. Ansaldo de Ansaldis, Romae 1711, dec. 30, nn. 50 ss.; Sacrae Rotae Romanae Decisionum Recentiorum..., IV/3, Venetiis 1697, dec. 656.

10 Sacrae Rotae Romanae decisionum Recentiorum..., V/1, Romae 1642, dec. 380, n. 33; Sacrae Rotae Romanae Decisionum Recentiorum... XI, Venetiis 1697, dec. 301, nn. 3 ss.; Sacrae Rotae Romanae Decisionum Recentiorum..., VI, Venetiis 1697, dec. 73. V. ESMEIN, (1935), II, pp. 225-228.

11 LE BRAS, (1927), coll 2193 ss.; DAUVILLIER, J. (1933), pp. 55-75; GAUDEMET, J. (1987), pp. 180 ss.; BRUNDAGE, J. A. (1993), "Concubinage and Marriage in Medieval Canon Law", dans Sex, Law and Marriage in the Middle Ages, Great Yarmouth, pp. 1-17, surtout pp. 8-9.

12 V. TAMASSIA, N. (1910), La famiglia italiana nei secoli decimoquinto e decimo sesto, Milano, Palermo, Napoli; ROBERTI, M. (1932), Svolgimento storico della famiglia italiana, Milano; 
"SUA VI, SUA NATURA, SUA SPONTE SACRUM". LE MARIAGE DANS LA JURISPRUDENCE DE LA ROTE ROMAINE... Angela SANTANGELO CORDIANI

ROBERTI, M. (1935), Svolgimento storico del diritto privato in Italia, III, La famiglia, Padova; TORELLI, P. (1947), Lezioni di storia del diritto italiano. Diritto privato. La famiglia, Milano; OURLIAC, P. et DE MALAFOSSE, J. (1968), Histoire du droit privé, Paris; COZZI, G. (1983), "Padri, figli e matrimoni clandestini", dans MANOUKIAN, A. (édité par), I vincoli familiari in Italia. Dal secolo XI al secolo XX, Bologna, pp. 195 ss.; KLAPISCH-ZUBER, Ch. (1988), "Zaccaria, o il padre spodestato. I riti nuziali in Toscana tra Giotto e il Concilio di Trento", dans KLAPISCH-ZUBER, Ch., La famiglia e le donne nel Rinascimento a Firenze, Roma-Bari, pp. 110 ss.; AZNAR GIL, F. R. (1989), La institución matrimonial en la Hispania cristiana bajo-medieval (1215-1563), Salamanca; PETOT, P. (1992), Histoire du droit privé français. La famille, Paris; Le droit de la famille en Europe. Son évolution depuis l'antiquité jusqu'à nos jours (1992), Actes des Journées internationales d'histoire du droit, Strasbourg; DI RENZO VILLATA, G. (1995), "Persone e famiglia nel diritto medievale e moderno", dans Digesto delle discipline privatistiche. Sezione civile, XIII, Torino, pp. 457-526; CAVINA, M. (2007), Il padre spodestato. L'autorità paterna dall'antichità a oggi, Roma-Bari.

13 PRODI, P. (1989), "Il matrimonio tridentino e il problema dei figli illegittimi", dans Per Giuseppe Sebesta: scritti e nota bio-bibliografica per il settantesimo compleanno, a cura della Biblioteca Comunale di Trento, Trento, pp. 405-414.

14 Voir par exemple BRANDILEONE, F. (1906), "La celebrazione del matrimonio in Roma nel secolo XV ed il Concilio di Trento" e "Per la storia dei riti nuziali in Italia dans" dans BRANDILEONE, F., Saggi sulla storia della celebrazione del matrimonio in Italia, Milano, pp. 291-340, 489-499; TAMASSIA, N. (1911), La famiglia italiana nei secoli decimoquinto e decimosesto, Palermo, pp. 181-193; RASI, (1941), I, pp. 235-281; RASI, P. (1943), "La conclusione del matrimonio prima del Concilio di Trento", Rivista di storia del diritto italiano, vol. XVI, pp. 233-321; RASI, P. (1958), La conclusione del matrimonio nella dottrina prima del Concilio di Trento, Napoli; GAUDEMET, J. (1980), "Il legame matrimoniale nel XVII secolo. Legislazione canonica e tendenze laiche", dans BUONANNO, M. (édité par), Le funzioni sociali del matrimonio. Modelli e regole della scelta del coniuge dal XIV al XX secolo, Milano, pp. 73-74; MEGNA, L. (1985), "In margine ad alcune carte processuali di area vicentina: sponsali e matrimonio tra XVI e XVII secolo", dans POVOLO, C. (édité par), Bolzano Vicentino. Dimensione del sociale e vita economica in un villaggio della pianura vicentina (secoli XIV$X I X)$, Bolzano Vicentino, p. 316; KLAPISCH-ZUBER, (1988), pp. 110-111; DONAHUE, C. (1995), "Was there a change in marriage law in the late Middle Ages?", Rivista internazionale di diritto comune, VI, pp. 49-50; ZARRI, G. (1996), "Il matrimonio tridentino", dans PRODI et REINHARD, pp. 437-438; LOMBARDI, D. (1996), "Fidanzamenti e matrimoni dal Concilio di Trento alle riforme settecentesche", dans DE GIORGIO, M. et KLAPISCH-ZUBER, Ch. (édité par), Storia del matrimonio, Roma-Bari, p. 218; LOMBARDI, (2001), pp. 179-241; LOMBARDI, D. (2008), Storia del matrimonio. Dal Medioevo a oggi, Bologna, pp. 115-122; SEIDEL MENCHI, (2001), pp.17-60.

15 ESMEIN, (1935), II, pp. 295 ss.; JEMOLO, A. C. (1941), pp. 13 ss.; SCHOTT, H. (1954), pp. 33 ss.; NUZZO, L. (1998), pp. 351-396; FANTAPPIÉ, C. (2011), Storia del diritto canonico e delle istituzioni della Chiesa, Bologna, pp. 163 ss.

16 V. supra nt. 4.

17 V. par exemple Decisionum novissimarum diversorum, I, Venetiis 1607, dec. 209, nn. 6-7; dec. 429, n. 2; Sacrae Rotae Romanae Decisionum Recentiorum..., III/4, Romae 1646, dec. 460, n. 42; Sacrae Rotae Romanae Decisionum Recentiorum..., I, Venetiis 1697, dec. 72; Sacrae Rotae Romanae Decisiones nuperrimae, VIII, Romae 1761, dec. 137, n. 18.

18 Sacrae Rotae Romanae Decisionum Recentiorum..., X, Romae 1666, dec. 93, n. 11, dec. 300, n. 7; Sacrae Rotae Romanae Decisionum Recentiorum... XI, Venetiis 1697, dec. 301, nn. 2, 17 ss. et 32; Sacrae Rotae Romanae Decisionum Recentiorum..., XVIII/2, Venetiis 1697, dec. 405, incipit; Sacrae Rotae Romanae Decisionum Recentiorum..., XVIII/2, Venetiis 1697, dec. 405, nn. 9-11; Sacrae Rotae Romanae Decisionum Recentiorum..., IV/1, Venetiis 1697, dec. 204, 600 et 605; Sacrae Rotae Romanae Decisionum Recentiorum..., IV/2, Venetiis 1697, dec. 493; Sacrae Rotae Romanae Decisionum Recentiorum... XII, Venetiis 1716, dec. 23, nn. 7-8, dec. 227, incipit; dec. 317, n. 13; Sacrae Rotae Romanae Decisionum Recentiorum..., XIV, Venetiis 1761, dec. 67 , n. 8 ; dec. 93 , n. 4.

Revista de Estudios Jurídicos, UJAEN, España $\mid$ AÑO 2021 |NUM. 21, e6775 | ISSN 1576-124X 
19 Sacrae Rotae Romanae Decisionum Recentiorum..., III/4, Romae 1646, dec. 431, n. 85; dec. 493, n. 64; Sacrae Rotae Romanae Decisionum Recentiorum..., X, Romae 1666, dec. 19, n. 59; Sacrae Rotae Romanae Decisionum Recentiorum... XII, Venetiis 1716, dec. 86, incipit; Decisiones Sacrae Rotae Romanae coram Alexandro Tanario, I, Romae 1748, dec. 84, n. 15. Sacrae Rotae Romanae Decisionum Recentiorum..., III/4, Romae 1646, dec. 134, n. 18; dec. 398, n. 21; dec. 431, n. 60; Sacrae Rotae Romanae Decisionum Recentiorum..., IX/1, Venetiis 1716, dec. 21, nn. 25 et ss.; Decisiones Sacrae Rotae Romanae coram Rev. Patre Domino Hieronymo Crispo, III, Urbini 1728, dec. 468, n. 1; Decisiones Sacrae Rotae Romanae Coram bo. Me. R.P.D. Ansaldo de Ansaldis, II, Romae 1736, dec. 122, n. 52.

21 Sacrae Rotae Romanae Decisionum Recentiorum..., III/4, Romae 1646, dec. 431, nn. 83 et 86, com. 2.

Ibidem, dec. 105, n. 1; dec. 232, nn. 6 ss.; dec.431, nn. 10 ss.; dec. 526, n. 12; dec. 629, nn. 1 ss.; Sacrae Rotae Romanae Decisionum Novissimarum..., I, Romae 1642, dec. 264, n. 4; dec. 380, n. 33; dec. 389, nn. 34-35; Sacrae Rotae Romanae decisionum Recentiorum..., V/1, Romae 1642, dec. 380, nn. 34-36; Sacrae Rotae Romanae Decisionum Recentiorum..., XIII, Romae 1642, dec. 312, nn. 10-12, dec. 264, n. 5; Sacrae Rotae Romanae Decisionum Recentiorum... XI, Venetiis 1697, dec. 37, nn. 7 ss., dec. 334, n. 3; Sacrae Rotae Romanae Decisionum Recentiorum..., IX/1, Venetiis 1716, dec. 21, n. 21; dec. 190, nn. 32 ss.; Sacrae Rotae Romanae Decisionum Recentiorum... XII, Venetiis 1716, dec. 72, n. 8; dec. 86, n. 38; Sacrae Rotae Romanae Decisionum Recentiorum..., XIV, Venetiis 1761, dec. 433, n. 13.

DE LUCA, G. B. (1680), Il Principe cristiano pratico, Roma, pp. 362 ss. Je me limite ici à indiquer les cadres de synthèse fournis par MAZZACANE, A. (1990), "De Luca, Giovanni Battista", dans Dizionario biografico degli italiani, XXXVIII, Roma, pp. 340-347; BIROCCHI, I. et FABBRICATORE, E. (2013), "De Luca, Giovanni Battista", dans BIROCCHI, I., CORTESE, E., MATTONE, A. et MILETTI, M. N. (édité par), Dizionario biografico dei giuristi italiani (XII-XX secolo), I, Bologna, pp. 685-687

24 Sacrae Rotae Romanae Decisionum Recentiorum..., X, Romae 1666, dec. 233, nn. 23-28; Sacrae Rotae Romanae Decisiones Recentiores, XVII, Romae 1678, dec. 75, n. 13; Sacrae Rotae Romanae Decisionum Recentiorum..., XVIII/2, Venetiis 1697, dec. 490, n. 1; Sacrae Rotae Romanae Decisionum Recentiorum..., XIX/2, Romae 1703, dec. 668, n. 20; Sacrae Rotae Romanae Decisionum Recentiorum..., IV, Venetiis 1697, dec. 625; Sacrae Rotae Romanae Decisionum Recentiorum..., IV/3, Venetiis 1697, dec. 629; Sacrae Rotae Romanae Decisionum Recentiorum..., XIV, Venetiis 1761, dec. 433, nn. 1-11, dec. 498, n. 16; Sacrae Rotae Romanae Decisionum Recentiorum..., X, Venetiis 1697, dec. 233; Index generalis rerum notabilium... in toto opere Decisionum S.R.R. coram R.P.D. Carolo Rezzonico, IV, Romae 1762, p. 194, v. Matrimonium.

25 Sacrae Rotae Romanae decisionum recentiorum..., V/1, Romae 1642, dec. 264, nn. 51 ss.; Sacrae Rotae Romanae Decisionum Recentiorum..., XIII, Romae 1642, dec. 264, nn. 7 ss., dec. 312, nn. 2-8; dec. 444, n. 9; dec. 445, nn. 9 ss.; Sacrae Rotae Romanae Decisionum Recentiorum..., XVIII/2, Venetiis 1697, dec. 779, n. 9.; Sacrae Rotae Romanae Decisionum Recentiorum..., XIX/2, Romae 1703, dec. 463, n. 2; Sacrae Rotae Romanae Decisionum Recentiorum..., III, Venetiis 1697, dec. 681 et 693; Sacrae Rotae Romanae Decisionum Recentiorum..., III, Venetiis 1697, dec. 374; Sacrae Rotae Romanae Decisionum Recentiorum..., X, Venetiis 1697, dec. 233; Decisiones Sacrae Rotae Romanae coram Alexandro Tanario, I, Romae 1748, dec. 231, nn. 13 ss.

26 Decisiones Sacrae Rotae compendiariae... Per R.P.D. Achillem de Grassis, Romae 1590, decc. 171 et 175; Decisionum novissimarum diversorum..., I, Venetiis 1607, dec. 340, n. 1; Sacrae Rotae Romanae Decisionum novissimarum..., I, Romae 1642, dec. 15, n.4; dec. 16, n.11; dec. 264, n. 20 et n. 52; Sacrae Rotae Romanae decisionum recentiorum..., V/1, Romae 1642, dec. 264, n. 52; Sacrae Rotae Romanae Decisionum Recentiorum..., XIII, Romae 1642, dec. 264, n. 7, dec. 312, nn. 2-8; dec. 444, n. 9; dec. 445, n. 9; Sacrae Rotae Romanae Decisionum Recentiorum..., III/4, Romae 1646, dec. 385, n. 9; Sacrae Rotae Romanae Decisionum Recentiorum..., X, Romae 1666, dec. 233, nn. 17 ss.; Sacrae Rotae Romanae Decisionum Recentiorum... XI, Venetiis 1697, dec. 301, n. 6, dec. 375, nn. 2 ss.; Sacrae Rotae Romanae Decisionum Recentiorum..., XVIII/2, Venetiis 1697, dec. 779, n. 9.; Sacrae Rotae Romanae Decisionum Recentiorum..., XIX/2, Romae 1703, dec. 463, n. 2; Sacrae 
Rotae Romanae Decisionum Recentiorum..., III, Venetiis 1697, dec. 681 et 693; Sacrae Rotae Romanae Decisionum Recentiorum..., III, Venetiis 1697, dec. 374; Sacrae Rotae Romanae Decisionum Recentiorum... XII, Venetiis 1716, dec. 72, nn. 5-6, dec. 86, n. 36, dec. 117, n. 38, dec. 227, n. 5, dec. 317, n. 8; Sacrae Rotae Romanae Decisionum Recentiorum..., XVIII/1, Venetiis 1716, dec. 37, nn. 5-8, dec. 233, n. 14, dec. 370, nn. 5-7; Sacrae Rotae Romanae Decisionum Recentiorum..., X, Venetiis 1697, dec. 233; Decisiones Sacrae Rotae Romanae coram Alexandro Tanario, I, Romae 1748, dec. 231, n. 13.

27 Decisionum novissimarum diversorum, I, Venetiis 1607, dec. 34, n. 19; dec. 79, n. 2; dec. 92, n. 1; dec. 130, n. 6; dec. 357, n. 10; dec. 470, n. 5; dec. 477, n. 3; Sacrae Rotae Romanae Decisionum Novissimarum..., I, Romae 1642, dec. 264, nn. 11-12 et 53; Sacrae Rotae Romanae decisionum Recentiorum..., V/1, Romae 1642, dec. 264, nn. 10 ss.; Sacrae Rotae Romanae Decisionum Recentiorum..., XIII, Romae 1642, dec. 312, n. 19, dec. 389, n. 13; Sacrae Rotae Romanae Decisionum Recentiorum..., X, Romae 1666, dec. 214, nn. 13-15, dec. 233, n. 16; Sacrae Rotae Romanae Decisionum Recentiorum..., II, Venetiis 1697, dec. 772; Sacrae Rotae Romanae Decisionum Recentiorum... XI, Venetiis 1697, dec. 301, nn. 35 ss.; Sacrae Rotae Romanae Decisionum Recentiorum..., XVIII/2, Venetiis 1697, dec. 779, nn. 5 ss.; Sacrae Rotae Romanae Decisionum Recentiorum..., I, Venetiis 1697, dec. 310; Sacrae Rotae Romanae Decisionum Recentiorum..., II, Venetiis 1697, dec. 341; Sacrae Rotae Romanae Decisionum Recentiorum..., V, Venetiis 1697, dec. 264; Sacrae Rotae Romanae Decisionum Recentiorum... XII, Venetiis 1716, dec. 72, n. 6, dec. 86, nn. 5-8, dec. 248, nn. 5 ss.; Sacrae Rotae Romanae Decisionum Recentiorum..., XVIII/1, Venetiis 1716, dec. 133, nn. 14-16, dec. 370, n. 7; Sacrae Rotae Romanae Decisionum Recentiorum..., XIV, Venetiis 1761, dec. 67, n. 4, dec. 433, n. 15. V. aussi infra nt. 58.

28 GAUDEMET, J. (1989), p. 231.

29 Sacrae Rotae Romanae Decisionum Recentiorum..., III/4, Romae 1646, dec. 625, nn. 15-16; Sacrae Rotae Romanae Decisionum Recentiorum..., IV/1, Venetiis 1697, dec. 74; Sacrae Rotae Romanae Decisionum Recentiorum... XII, Venetiis 1716, dec. 317, n. 17; Sacrae Rotae Romanae Decisionum Recentiorum..., VIII, Romae 1759, dec. 189, nn. 3 ss.; Sacrae Rotae Romanae Decisionum Recentiorum..., XIII, Romae 1762, dec. 312, n. 4.

30 MANZONI, A. (1840), I promessi sposi, Milano, cap. 8.

31 GAUDEMET, J. (1989), pp. 225 ss.

32 Decisionum novissimarum diversorum, I, Venetiis 1607, dec. 497, nn. 1 ss.; Sacrae Rotae Romanae Decisionum Recentiorum..., III/4, Romae 1646, dec. 258, n. 8; dec. 656, nn. 7-8; Sacrae Rotae Romanae Decisionum Recentiorum..., X, Romae 1666, dec. 19; Sacrae Rotae Romanae Decisionum Recentiorum..., XVIII/2, Venetiis 1697, dec. 621, nn. 1 ss.; Sacrae Rotae Romanae Decisionum Recentiorum..., XIV, Venetiis 1761, dec. 242, n. 10.

33 "Justitiae publicae honestatis impedimentum, ubi sponsalia quacunque ratione valida non erunt, S. Synodus prorsus tollit; ubi autem valida fuerint, primum gradum non excedant: quoniam in ulterioribus gradibus jam non potest huiusmodi prohibitio absque dispendio observari" (Sacrosanctum Concilium Tridentinum cit., Decretum de reformatione matrimonii, Caput III, p. 201).

34 Il s'agit de certains passages de l'Exode (28, 15-16: X 5.16.1) et du Deutéronome (22, 28-29: X 5.6.2). Cf. ALESSI, G. (1990), "Il gioco degli scambi: seduzione e risarcimento nella casistica cattolica del XVI e XVII secolo", Quaderni storici, vol. 75, pp. 805-831, spécialement pp. 809-811.

$35 \quad$ Voir supra nt. 16.

36 Sacrae Rotae Romanae Decisionum Recentiorum..., X, Romae 1666, dec. 19, nn. 38-39; Sacrae Rotae Romanae Decisionum Recentiorum..., IV/2, Venetiis 1697, dec. 258. V. aussi Decisionum novissimarum diversorum, I, Venetiis 1607, dec. 209, nn. 6-7; dec. 429, n. 2; Sacrae Rotae Romanae Decisionum Recentiorum..., III/4, Romae 1646, dec. 460, n. 42; Sacrae Rotae Romanae Decisionum Recentiorum..., I, Venetiis 1697, dec. 72; Sacrae Rotae Romanae Decisiones nuperrimae, VIII, Romae 1761, dec. 137, n. 18.

37 Sur ce thème v. SCHIAPPOLI, D. (1905), Diritto penale canonico, Milano, pp. 875-892; BIANCHEDI, C. (1927), "Violenza carnale", dans Digesto Italiano, 24, Torino, col. 1064-1135; GABRIELI, F. (1940), "Violenza carnale", dans Novissimo Digesto Italiano, 22/2, Torino, col. 1069-1079; CALISSE, C. (1941), Principii di diritto penale nei giuristi del rinascimento (sec. 
XIII-XVI), Milano; LONGO, M. (1975), "Vis", dans Novissimo Digesto italiano, 20, Torino, col. 989-994. Plus récemment AA.VV. (1985), Violence et violences, Lyon; PADOVANI, T. (1989), "Costringimento fisico e psichico", dans Digesto delle discipline penalistiche, 3, Torino, pp. 209-214; RAYNAUD, C. (1991), La violence au moyen âge (XIII-XIV siècle), Paris; ROSONI, I. (1993), "Violenza (dir. interm.)", dans Enciclopedia del diritto, 46, Milano, pp. 843-858; MASSETTO, G. P. (1994), "I reati nell'opera di Giulio Claro", dans Saggi di storia del diritto penale lombardo, Milano, pp. 61-227; CAZZETTA, G. (1999), Praesumitur seducta. Onestà e consenso femminile nella cultura giuridica moderna, Milano; SEIDEL MENCHI, S. et QUAGLIONI, D. (édité par) (2004), Trasgressioni. Seduzione, concubinato, adulterio, bigamia (XIV-XVIII secolo), Bologna; SANTANGELO CORDANI, A. (2011), "Vis grata puellis. Bonnes moeurs et violence sexuelle dans la Praxis et theorica criminalis de Prospero Farinacci", dans CHAMOCHO, M. A. (édité par), Droit et moeurs. Implication et influence des moeurs dans la configuration du droit. Actes des Journées internationales de la Société d'histoire du droit, Jaén-Baeza, 3-6 juin 2010, Jaén, Universidad de Jaén, pp. 319-332; COCCHIARA, M. A. (édité par) (2014), Violenza di genere, politica e istituzioni, Milano; FECI, S. et SCHETTINI, L. (édité par) (2017), La violenza contro le donne nella storia: contesti, linguaggi, politiche del diritto (secoli XV-XXI), Roma; ESPOSITO, A., FRANCESCHI, F. et PICCINNI G. (édité par) (2018), Violenza alle donne: una prospettiva medievale, Bologna.

38 CAZZETTA, (1999), surtout pp. 57 ss.

39 Sacrae Rotae Romanae Decisionum Recentiorum..., X, Romae 1666, dec. 93, n. 11, dec. 300, n. 7; Sacrae Rotae Romanae Decisionum Recentiorum... XI, Venetiis 1697, dec. 301, nn. 2,17 ss. et 32; Sacrae Rotae Romanae Decisionum Recentiorum..., XVIII/2, Venetiis 1697, dec. 405, incipit; Sacrae Rotae Romanae Decisionum Recentiorum..., XVIII/2, Venetiis 1697, dec. 405, nn. 9-11; Sacrae Rotae Romanae Decisionum Recentiorum..., IV/1, Venetiis 1697, dec. 204, 600 et 605; Sacrae Rotae Romanae Decisionum Recentiorum..., IV/2, Venetiis 1697, dec. 493; Sacrae Rotae Romanae Decisionum Recentiorum... XII, Venetiis 1716, dec. 23, nn. 7-8, dec. 227, incipit; dec. 317, n. 13; Sacrae Rotae Romanae Decisionum Recentiorum..., XIV, Venetiis 1761 , dec. 67, n. 8 ; dec. 93 , n. 4.

40 ALESSI, (1990), pp. 810 ss.

41 Supra nt. 33.

42 Voir GRAZIOLI, M. (1911-1915), "Ratto", dans Digesto Italiano, 20/1, Torino, col. 172-195; GABRIELI, F. (1939), "Ratto", dans Novissimo Digesto Italiano, 10, Torino, col. 1122-1138; NAZ, R. (1965), "Rapt", dans Dictionnaire de droit canonique, 7, Paris, pp. 454-460; TOMASELLI, S. et PORTER, R. (édité par) (1986), Rape. An historical and cultural Enquiry, Oxford; MASSETTO, G. P. (1987), "Ratto (dir. interm.)", dans Enciclopedia del diritto, 38, Milano, pp. 725-743.

43 Corpus iuris civilis, ed. Mommsen-Krueger, Berlin, 1963: C. 9.13.1.2 ; Nov. 143 et 150 (“qui enim tale stare matrimonium, etsi rapta voluerit, prohibuimus").

44 Corpus iuris canonici, ed. A. Friedberg, Leipzig, 1879 (Nachdruck Graz 1995): X 5.17.7 définit le mariage valable "si prior dissensio transeat postmodum in consensum, et quod ante displicuit, tandem incipiat complacere".

45 Le juriste espagnol Thomàs Sanchez, au nom du favor matrimonii, réputait impossible que la décrétale de Innocent III insérée dans le Liber Extra "cum verbis tam ambiguis, et obscuris voluisse irritare matrimonium, quod est res tanti momenti” (SÁNCHEZ, T. (1612), Disputationum de sancto matrimonii sacramento libri decem, Venetiis, lib. VII, disp. XII, n. 41). Suivant le grande criminaliste romaine Prospero Farinacci “...eandem limitationem non procedere, quando matrimonium sequutum fuit, puella existente in libertate extra raptorum potestate, in domo scilicet parentum, seu consanguineorum, secus si adhuc puella in raptorum potestate existente raptori nupserit [...] licet [Tomás Sánchez] videatur declarare hoc non procedere, quando constaret, puellam, etsi in raptoris potestatem existentem vere, et libere matrimonio consensisse, ego tamen nescio videre quomodo possit constare, quando rapta in raptoris potestate consistit" (FARINACCIUS, P. (1613), Praxis et theorica criminalis pars quarta, Lugduni, q. 145, Raptus, n. 28).

46 "Decernit S. Synodus, inter raptorem et raptam, quamdiu ipsa in potestate raptoris manserit, nullum posse consistere matrimonium, quod si rapta, a raptore separata et in loco tuto et libero constituta, illum in virum habere consenserit: eam raptor in uxorem habeat"; donc "raptus pro 
eo tempore est impedimentum dirimens" (Sacrosanctum Concilium Tridentinum cit., Decretum de reformatione matrimonii, Caput VI, p. 202).

47 Sacrae Rotae Romanae Decisionum Novissimarum..., I, Romae 1642, dec. 16, n. 15; dec. 264, n. 13 et 39; dec. 316, nn. 36 ss.; Sacrae Rotae Romanae decisionum Recentiorum..., V/1, Romae 1642, dec. 264, nn. 32-39, dec. 316, nn. 15 ss.; Sacrae Rotae Romanae Decisionum Recentiorum..., V, Venetiis 1697, dec. 316; Sacrae Rotae Romanae Decisionum Recentiorum..., XIV, Venetiis 1761, dec. 498, incipit.

48 ESMEIN, (1935), II, pp. 225-228. V. par exemple Sacrae Rotae Romanae Decisionum Recentiorum..., XIV, Venetiis 1761, dec. 535, n. 51.

49 Sacrosanctum Concilium Tridentinum cit., Decretum de sacramentis, De Baptismo, c. IV, p. 50. V. Sacrae Rotae Romanae Decisionum Recentiorum..., XIV, Venetiis 1761, dec. 535, nn. 50 ss. "Multi sunti, qui vagantur, et incertas habere fides, et, ut improbi sunt ingenii, prima uxore relicta, aliam, et plerumque plures, illa vivente, diversis in locis ducunt; cui morbo cupiens sancra Synodus occurrere, omnes, ad quos spectat, paterne monet, ne hoc genus hominum vagantium ad matrimonium facile recipiant; magistratus etiam saeculares hortatur, ut eos severe coerceant: Parochis autem praecipit, ne illorum matrimoniis intersint, nisi prius diligentem inquisitionem fecerint, et, re ad Ordinariujm delata, ab eo licentiam id faciendi obtinuerint" (Sacrosanctum Concilium Tridentinum cit., Decretum de reformatione matrimonii, Caput VII, pp. 202-203). V. par exemple Sacrae Rotae Romanae Decisionum Recentiorum..., XIV, Venetiis 1761, dec. 535, nn. $42-49$ et 54.

51 Sacrosanctum Concilium Tridentinum cit., Sessio XXIV, pp. 193-197. V. ESMEIN, (1935), II, pp. 128 ss.; GISMONDI, P. (1949), "La celebrazione del matrimonio secondo la dottrina e la legislazione canonica sino al Concilio tridentino", dans Ephemerides Iuris canonici, V, pp. 3-40, surtout pp. 21 ss.; GAUDEMET, (1987), pp. 168 et 177 ss.; RASI, A. (1949), "La separatio thori e le norme del Concilio di Trento", Rivista di storia del diritto italiano, 21, pp. 231 ss.; VACCARI, P. (1970), "Separazione personale dei coniugi (Storia del diritto)", dans Novissimo Digesto italiano, XVII, Torino, pp. 6 ss.; BRUNDAGE, J. A. (1987), Law, Sex and Christian Society in Medieval Europe, Chicago and London, pp. 337-341; DI RENZO VILLATA, G. (1989), "Separazione personale (storia)", dans Enciclopedia del diritto, 41, Milano, pp. 1350-1376, surtout pp. 1360 ss.; BRUNDAGE, J. A. (1993), "Marriage and Sexuality in the Decretals of Pope Alexander III", dans BRUNDAGE, (1993); MARCHETTO, G. (2008), Il divorzio imperfetto. I giuristi medievali e la separazione dei coniugi, Bologna.

52 À côté des textes cités supra à la note 50, voir aussi CONDE CID, J. C. (2014), "L'origine del privilegio paolino", Ius Ecclesiae. Rivista internazionale di diritto canonico, vol. XXVI, $\mathrm{n}^{\circ} 2$, pp. 335-358.

53 Decisionum novissimarum diversorum, I, Venetiis 1607, dec. 121, n. 26.

54 Auxquels s'ajoutaient certains cas spécifiques relatifs à la condition des polygames en Inde, prévus par certaines constitutions apostoliques: Paul III, Altitudo (1527), Pie V, Romani Pontificis (1571), Grégoire XIII, Populis (1585).

55 Sacrosanctum Concilium Tridentinum cit., Sessio XXIV, can. VIII, p. 196 : "Si quis dixerit, Ecclesiam errare, cum ob multas causas separationem inter coniuges, quod torum, sed quoad cohabitationem, ad certum, incertumve tempus fieri posse decernit; anathema fit".

56 Sacrae Rotae Romanae Decisionum Novissimarum..., I, Romae 1642, dec. 264, n. 24; Sacrae Rotae Romanae Decisionum Recentiorum... XI, Venetiis 1697, dec. 301, nn. 29 ss.; Decisiones Sacrae Rotae Romanae coram Alexandro Tanario, I, Romae 1748, dec. 231, n. 12; ibidem, II, dec. 227, n. 1; Decisiones Sacrae Rotae Romanae coram Rev. Patre Domino Hieronymo Crispo, III, Urbini 1728, dec. 569, n. 5. À propos des processus de nullité des mariages v. ERRERA, A. (2003), "La procedura dei tribunali ecclesiastici in materia matrimoniale: cenni di un'evoluzione storica”, dans PADOA SCHIOPPA, A., DI RENZO VILLATA, G. et MASSETTO, G. P. (édité par), Amicitiae pignus. Studi in ricordo di Adriano Cavanna, II, Milano, pp. 966-995, surtout pp. 969 ss.

57 Sacrae Rotae Romanae Decisionum Recentiorum..., III/4, Romae 1646, dec. 742, n. 23; Sacrae Rotae Romanae Decisionum Recentiorum cit., IV/1, Venetiis 1697, dec. 49, p. 43; Sacrae Rotae Romanae Decisiones coram Buratto, III, Romae 1637, dec. 815, pp. 117 ss.; ivi, dec. 801, XVIII/2, pp. 469 ss.; Sacrae Rotae Romanae Decisionum Recentiorum..., I, Venetiis 1697, dec. 441; VI, decc. 155, 202, 280. 
$58 \quad$ Corpus iuris canonici cit., X 2.20.27.

59 Sacrae Roate Romanae, Decisionum Recentiorum cit., XVIII/2, Venetiis 1697, dec. 818 (1681), pp. 493-494; XII, dec. 337, n. 6 et 14.V. ROSONI, I. (1995), Quae singula non prosunt collecta iuvant. La teoria della prova indiziaria nell'età medievale e moderna, Milano, surtout pp. 97-191, à côté de FIORELLI, P. (1953), La tortura giudiziaria nel diritto comune, I, Milano, pp. 10-50. Voir aussi BELLAVISTA, G. (1971), "Indizi”, dans Enciclopedia del diritto, 21, Milano, pp. 224-232; CAVANNA, A. (1975), La codificazione penale in Italia. Le origini lombarde, Milano, pp. 197 ss.; ALESSI PALAZZOLO, G. (1979), Prova legale e pena. La crisi del sistema tra evo medio e moderno, Napoli, pp. 99-177; MASSETTO, G. P. (1994), "La prassi giuridica lombarda nell'opera di Giulio Claro (1525-1575)", dans Saggi di storia del diritto penale lombardo (Secc. XVI-XVIII), Milano, pp. 11-59, surtout pp. 18-19; CORDERO, F. (1986), Criminalia. Nascita dei sistemi penali, Roma-Bari, pp. 259-267; DEZZA, E. (1992), Tommaso Nani e la dottrina dell'indizio nell'età dei lumi, Milano; MARCHETTI, P. (1994), Testis contra se. L'imputato come fonte di prova nel processo penale dell'età moderna, Milano, surtout pp. 88-111; MECCARELLI, M. (1998), Arbitrium. Un aspetto sistematico degli ordinamenti giuridici in età di diritto comune, Milano, pp. 240-254.

60 Decisiones Rotae Romanae noviter novissimarum a P. Farinacio collectarum centuriae novem, Lugduni 1617, dec. 751 (1603), p. 415.

61 Decisiones Sacrae Rotae Romanae CCCLXXII, criminum et testium probationem in secundo praesertim responsorum criminalium P. Farinaccii volumine pertractatam respicientes, Lugduni 1616, dec. 302. Voir MINNUCCI, V. G. (2020), "Viro quaenam castigatio in uxorem permittatur'. La separazione fra coniugi ex saevitia in una decisione giudiziale dell'età moderna", dans SANTANGELO CORDANI, A. et ZICCARDI, G. (édité par), Tra odio e (dis)amore. Violenza di genere e violenza sui minori dalla prospettiva storica all'era digitale, Collana Università degli Studi di Milano, Facoltà di Giurisprudenza, Pubblicazioni del Centro di Studi sulla Giustizia, Milano, pp. 19-42.

62 Sacrae Rotae Romanae Decisiones coram Buratto cit., III, dec. 815 (du 1624), pp. 117 ss.; Decisiones Rotae Romanae coram Bichio, II, Romae 1671, dec. 412 (du 1650), pp. 22 ss.; Decisiones Sacrae Rotae Romanae CCCLXXII cit., dec. 371 (du 1613), pp. 302 ss.

63 Sacrae Rotae Romanae Decisionum cit., XVI, 1697, dec. 99, pp. 113ss.; Decisiones Sacrae Rotae Romanae CCCLXXII cit., dec. 371 cit., pp. 302 ss.; Sacrae Rotae Romanae Decisionum Recentiorum... I, Venetiis 1716, decc. 155, 202, 280, 441.

64 Par exemple Sacrae Rotae Romanae Decisionum cit., V/1, 1697, dec. 352 (du 1630), pp. 502 ss. 65 Ibidem, VI, dec. 202 (du 1633), pp. 286 ss.

66 Mais pas seulement: Sacrae Rotae Romanae Decisionum Recentiorum..., II, Venetiis 1697, dec. 781.

67 Sacrae Rotae Romanae Decisionum Recentiorum..., III/4, Romae 1646, dec. 392, nn 11 ss.; dec. 393, n. 34; dec. 445, n. 5; Sacrae Rotae Romanae Decisionum Recentiorum..., I, Venetiis 1697, dec. 695; Sacrae Rotae Romanae Decisionum Recentiorum..., IV, Venetiis 1697, dec. 392; Sacrae Rotae Romanae Decisionum Recentiorum..., IV/2, Venetiis 1697, dec. 445.

68 GAUDEMET, (1989), pp. 318-319.

69 Sacrae Rotae Romanae decisionum Recentiorum..., V/1, Romae 1642, dec. 138, n. 11; Sacrae Rotae Romanae Decisionum Recentiorum..., III/4, Romae 1646, dec. 392, n. 26; Sacrae Rotae Romanae Decisionum Recentiorum..., XVIII/1, Venetiis 1716, dec. 360, nn. 5 et 10.

70 Voir l'absence de decisiones matrimoniales dans: Sacrae Rorae Romanae Decisiones, Romae 1783; Decisiones Sacrae Rotae Romanae, Romae 1790; Decisiones Sacrae Rotae Romanae, Romae 1802; Decisiones Sacrae Rotae Romanae, Romae 1822; Decisiones Sacrae Rotae Romanae, Romae 1827; Decisiones Sacrae Rotae Romanae, Romae 1828; Decisiones Sacrae Rotae Romanae, Romae 1832; Decisiones Sacrae Rotae Romanae, Romae 1835.

71 Parmi les études les plus récentes voir PO-CHIA HSIA, (2001), pp. 19-38; PROSPERI, (2015), pp. 183 ss.; BASDEVANT-GAUDEMET, (2014), pp. 39-54; GARCÍA HOURCADE, (2015), pp. 215 ss.; AL KALAK, (2019), pp. 93 ss.; FANTAPPIÉ, (2011), pp. 185 ss.

72 Cost. ap. Sapienti consilio, dans Acta Apostolicae Sedis., I, 1909, pp. 7-19. Cfr. JANKOWIAK, E. (2007), La Curie romaine de Pie IX à Pie X, Roma, pp. 53 ss. 
“SUA VI, SUA NATURA, SUA SPONTE SACRUM". LE MARIAGE DANS LA JURISPRUDENCE DE LA ROTE ROMAINE... Angela SANTANGELO CORDIANI

38

73 MORONI, (1857), surtout pp. 270 ss.; ROBERTI, (1940), pp. 519 ss.; LEFEBVRE, (1965), pp. 762 ss.; DELLA ROCCA, (1973), en particulier pp. 755 ss.; MONETA, (1989), pp. 148-149; SPINELLI, (1992), pp. 77-80.

74 Coram Lega Habitae S.R. Rotae decisiones sive sententiae, Romae 1926, dec. 10, pp. 147-154; dec. 22, pp. 274-282.

75 Ibidem, dec. 20, pp. 248-267; dec. 24, pp. 292-301; dec. 28, pp. 334-340.

76 Ibidem, dec. 29, pp. 341-352; dec. 36, pp. 431-444.

77 Ibidem, dec. 9, pp. 132-146; dec. 31, pp. 352-359.

78 Ibidem, dec. 8, pp. 125-131; dec. 34, pp. 411-418

79 Ibidem, dec. 17, pp. 223-232.

80 Loi qui rétablit le Divorce, 27 juillet $1884\left(\mathrm{~N}^{\circ} 14485\right)$, dans Bulletin des lois de la République française, n. 859, pp. 85-88.

81 Codex iuris canonici, Romae 1917. Cfr. FANTAPPIÉ, (2011), pp. 256 ss.; FANTAPPIÉ, C. (2017), "El Código de derecho canónico de 1917 y su repercusión en la vida de la Iglesia", dans Separata 'Ius communionis', vol 5, cuad. 2, Universidad San Dámaso, pp. 209-224.

82 Cann. 1960-1992.

83 "Ea tantum sponsalia habentur valida et canonicos sortiuntur effectus, quae contracta fuerint per scripturam subsignatam a partibus et vel a parocho, aut loci Ordinario, vel saltem a duobus testibus" (Ex S. Congregatione Concilii Decretum Ne Temere, De sponsalibus et matrimonio, iussu et auctoritate SS. D. N. Pii Papae X, Datum Roma e die $2^{\circ}$ mensis Augustii anni 1907, De sponsalibus, I.). Cf. Can. 1017.

84 GAUDEMET, (1987), pp. 320-323.

85 Can. 1067.

86 Can. $1068 \S 1$.

87 "Ea tantum matrimonia valida sunt, quae coontrahuntur coram parocho vel loci Ordinario" (Decretum Ne Temere cit., De matrimonio, III). Cf. Can. 1094.

88 Can. 1081.

89 Can. $1013 \S 1$. Can. 1081, § 2.

90 Can. 1118.

91 Can. 1120. V. supra nt. 51.

92 Can. 1119.

93 Can. 1129.

94 Cann. 1094-1096. 